\title{
The Median Preoptic Nucleus Reciprocally Modulates Activity of Arousal-Related and Sleep-Related Neurons in the Perifornical Lateral Hypothalamus
}

\author{
Natalia Suntsova, ${ }^{1,2,4}$ Ruben Guzman-Marin, ${ }^{1,2}$ Sunil Kumar, ${ }^{1,3}$ Md. Noor Alam, ${ }^{1,2}$ Ronald Szymusiak, ${ }^{1,3}$ and \\ Dennis McGinty ${ }^{1,2}$ \\ ${ }^{1}$ Research Service, Veterans Affairs Greater Los Angeles Healthcare System, North Hills, California 91343, Departments of ${ }^{2}$ Psychology and ${ }^{3}$ Medicine, \\ University of California Los Angeles, Los Angeles, California 90095, and ${ }^{4}$ A. B. Kogan Research Institute for Neurocybernetics, Rostov State University, \\ Rostov-on-Don 344091, Russia
}

The perifornical-lateral hypothalamic area $(\mathrm{PF} / \mathrm{LH})$ contains neuronal groups playing an important role in control of waking and sleep. Among the brain regions that regulate behavioral states, one of the strongest sources of projections to the PF/LH is the median preoptic nucleus (MnPN) containing a sleep-active neuronal population. To evaluate the role of MnPN afferents in the control of PF/LH neuronal activity, we studied the responses of PF/LH cells to electrical stimulation or local chemical manipulation of the MnPN in freely moving rats. Single-pulse electrical stimulation evoked responses in 79\% of recorded PF/LH neurons. No cells were activated antidromically. Direct and indirect transynaptic effects depended on sleep-wake discharge pattern of PF/LH cells. The majority of arousal-related neurons, that is, cells discharging at maximal rates during active waking (AW) or during AW and rapid eye movement (REM) sleep, exhibited exclusively or initially inhibitory responses to stimulation. Sleep-related neurons, the cells with elevated discharge during non-REM and REM sleep or selectively active in REM sleep, exhibited exclusively or initially excitatory responses. Activation of the MnPN via microdialytic application of L-glutamate or bicuculline resulted in reduced discharge of arousal-related and in excitation of sleeprelated PF/LH neurons. Deactivation of the MnPN with muscimol caused opposite effects. The results indicate that the MnPN contains subset(s) of neurons, which exert inhibitory control over arousal-related and excitatory control over sleep-related PF/LH neurons. We hypothesize that MnPN sleep-active neuronal group has both inhibitory and excitatory outputs that participate in the inhibitory control of arousal-promoting PF/LH mechanisms.

Key words: perifornical lateral hypothalamus; median preoptic nucleus; electrical stimulation; microdialysis; neuronal activity; sleepwaking cycle

\section{Introduction}

The posterior lateral hypothalamus contains several interacting neuronal populations critically implicated in the control of waking, including histaminergic, glutamatergic, and peptidergic neurons (Lin, 2000; Gerashchenko and Shiromani, 2004). Peptidergic cells producing hypocretins/orexins located within perifornical-lateral hypothalamic $(\mathrm{PF} / \mathrm{LH})$ area are thought to be one of the key components of brain arousal network (de Lecea and Sutcliffe, 2005; Jones and Muhlethaler, 2005; Sakurai, 2005; Saper et al., 2005).

The majority of PF/LH neurons, including hypocretin cells, exhibit increased neuronal discharge and c-Fos immunoreactivity during active waking (AW) compared with quiet waking

\footnotetext{
Received March 27, 2006; revised Jan. 8, 2007; accepted Jan. 9, 2007.

This work was supported by the Medical Research Service of the Department of Veterans Affairs, National Institutes of Health Grants MH63323, MH47480, HL60296, and NS-50939, and the J. Christian Gillin Research Grant from the Sleep Research Society Foundation (N.S.)

Correspondence should be addressed to Dennis McGinty, Research Service (151A3), Veterans Affairs Greater Los Angeles, Healthcare System, 16111 Plummer Street, North Hills, CA 91343. E-mail: dmcginty@ucla.edu.

D0I:10.1523/JNEUROSCI.3498-06.2007

Copyright $\odot 2007$ Society for Neuroscience $\quad$ 0270-6474/07/271616-15\$15.00/0
}

(QW) and non-rapid eye movement (NREM) sleep (Estabrooke et al., 2001; Torterolo et al., 2001; Alam et al., 2002; Koyama et al., 2003; Lee et al., 2005; Mileykovskiy et al., 2005). Current evidence suggests a role of GABAergic inhibition in the sleep-related inactivation of arousal-related PF/LH neurons and involvement of this mechanism in sleep control. It was shown that reverse microdialysis of the $\mathrm{GABA}_{\mathrm{A}}$ receptor antagonist bicuculline into the $\mathrm{PF} / \mathrm{LH}$ increased both the time spent awake and the number of c-Fos-positive hypocretin-immunoreactive and nonhypocretin PF/LH cells (Alam et al., 2005a). Application of the $\mathrm{GABA}_{\mathrm{A}}$ receptor agonists into the posterolateral hypothalamus (Lin et al., 1989; Sallanon et al., 1989) or the PF/LH (Thakkar et al., 2003) caused hypersomnia.

Recent evidence suggests that GABA-mediated control of the $\mathrm{PF} / \mathrm{LH}$ could originate in sleep-active neurons located within the preoptic area/basal forebrain. GABAergic cells showing sleeprelated c-Fos immunoreactivity are found within the ventrolateral preoptic area (VLPO) (Sherin et al., 1996) and the median preoptic nucleus (MnPN) (Gong et al., 2004). Sleep-active neurons located within these nuclei exhibit a specific pattern of enhanced discharge during both NREM and rapid eye movement 
(REM) sleep (Szymusiak et al., 1998; Suntsova et al., 2002), which is opposite to that demonstrated by wake-active PF/LH neurons. Warming of the preoptic area suppresses discharge of wakeactive PF/LH neurons (Methippara et al., 2003), whereas inhibition of this area with muscimol induces Fos in hypocretin and nonhypocretin PF/LH neurons (Satoh et al., 2004). Recent anatomical studies showed that the MnPN input to the $\mathrm{PF} / \mathrm{LH}$ is one of the heaviest among the structures involved in control of behavioral states (Yoshida et al., 2006). MnPN-PF/LH projection neurons include a subset of cells exhibiting sleep-related c-Fos immunoreactivity (Uschakov et al., 2006). These findings allow us to hypothesize that MnPN plays an important role in sleeprelated inhibitory modulation of hypocretin and nonhypocretin arousal-related PF/LH neurons.

An alternative or complementary source of inhibition of $\mathrm{PF} / \mathrm{LH}$ arousal-related cells could be local GABAergic neurons (Rosin et al., 2003) and/or cells containing an inhibitory peptide melanin concentrating hormone $(\mathrm{MCH})$. The latter are interconnected with hypocretin neurons (Bayer et al., 2002) and are likely to be a subset of PF/LH sleep-active cells (Verret et al., 2003; Modirrousta et al., 2005).

To determine the functional influence of the MnPN on PF/LH neuronal populations with different roles in behavioral state control, we examined the effects of electrical stimulation, chemical stimulation, and chemical inhibition of the MnPN on single-unit activity within the $\mathrm{PF} / \mathrm{LH}$ in rats.

\section{Materials and Methods}

Animals. Male Sprague Dawley rats (300-350 g; 8-10 weeks of age) were housed individually in Stand-Alone Raturn Animal Handling System (Bioanalytical Systems, West Lafayette, IN) placed inside an electrically shielded, sound-attenuated chamber. Rats were kept in a $12 \mathrm{~h}$ light/dark cycle with lights on at 8:00 A.M., designated as Zeitgeber time 0 (ZT0). Animals had ad libitum access to food and water. All experiments were performed in accordance with the National Research Council Guide for the Care and Use of Laboratory Animals. Animal use protocols were reviewed and approved by the Internal Animal Care and Use Committee of the Veterans Affairs Greater Los Angeles Healthcare System.

Surgery. Surgical procedures were performed under ketamine/xylazine anesthesia $(80 / 10 \mathrm{mg} / \mathrm{kg}$, i.p. respectively) and aseptic conditions.

For behavioral state assessment, stainless-steel screw EEG electrodes were placed into the skull over the frontal and parietal cortex and two Teflon-coated stainless-steel EMG wires were implanted into the dorsal neck muscles.

To record a single-unit activity within the $\mathrm{PF} / \mathrm{LH}$, a preassembled construction was used. It consisted of 10 Formvar-insulated stainlesssteel microwires $(20 \mu \mathrm{m})$ inserted into the 23 -gauge guide cannula that was attached to a mechanical microdrive anchored to the miniature electrical connector. A hole was trephined in the skull, centered at anterioposterior (AP), -3.14; mediolateral (ML), 1.2 (Paxinos and Watson, 1998). The guide cannula was lowered inside the brain to position its tip $3 \mathrm{~mm}$ above the target. After fixation of the entire assembly to the skull, the microwires were advanced through the guide cannula to a point corresponding to the PF/LH dorsal margin [horizontal $(\mathrm{H}), 8.2$ ].

To stimulate the MnPN electrically, animals were implanted with parallel bipolar Formvar-insulated tungsten electrodes $(80 \mu \mathrm{m} ; 10-20 \mathrm{k} \Omega$ at $1000 \mathrm{~Hz}$ ). Electrode wires targeted the most rostrovental and dorsocaudal portions of the MnPN (AP, $0.0 ; \mathrm{H}, 7.0$; and AP, $-0.46 ; \mathrm{H}, 5$, respectively) (Swanson, 1998) to provide stimulation of the entire structure (Fig. 1A).

To activate or inhibit the MnPN neuronal activity chemically, rats were implanted with a guide cannula for subsequent insertion of microdialysis probe. The guide cannula was implanted in the midline at a $15^{\circ}$ angle from the vertical with the tip located $3 \mathrm{~mm}$ from the target (AP, +0.12 ; ML, $0 ; \mathrm{H}, 7$ ).

Recording. The rats were allowed to recover from surgery for $7 \mathrm{~d}$, and then acclimated to experimental milieu for $3 \mathrm{~d}$. Experiments were performed on freely moving animals. EEG and EMG signals were recorded bipolarly using Polygraph model 78 amplifiers (Grass Instruments, Quincy, MA) with passbands set at 1-30 and 100-1000 Hz, respectively. Neuronal activity was recorded extracellularly using bipolar derivations from microwires (impedance at $1 \mathrm{kHz}, 500-800 \mathrm{k} \Omega$ ) and amplified by a differential AC amplifier (model 1700; A-M Systems, Carlsborg, WA) with low and high cutoff filters of $10 \mathrm{~Hz}$ and $10 \mathrm{kHz}$, respectively. During recording sessions, the microwires were advanced in 25-30 $\mu \mathrm{m}$ steps, until action potentials with signal-to-noise ratio $\geq 3$ were observed.

Bioelectrical signals were digitized and stored on hard drive for off-line analysis using Micro 1401 data acquisition interface and Spike2 software package (Cambridge Electronic Design, London, UK). Polygraphic data were digitized at a sampling rate $256 \mathrm{~Hz}$ and unit activity data at 10 or 25 $\mathrm{kHz}$ for waveform and wavemark data channels, respectively.

Electrical stimulation. Electrical stimulation of the MnPN was performed with $200 \mu$ s constant-current square pulses using A-65 Timer/ stimulator coupled with SC-100 constant-current monophasic stimulus isolation unit (Winston Electronics Company, Millbray, CA). Stimulation parameters were restricted because MnPN stimulation at current intensities $>150-200 \mu \mathrm{A}$ triggered absence-like seizures within a few seconds. To test PF/LH neuronal responses, the following nonepileptogenic stimulation paradigms were chosen. MnPN was stimulated at 100 $\mu \mathrm{A}$ current intensity with single pulses $(0.5$ pulses/s) or $5 \mathrm{~s}$ trains of stimuli followed by $150 \mathrm{~ms}$ period. Train stimulations were separated by at least $20 \mathrm{~s}$ recovery periods. Stimulation frequency within the trains was chosen based on median frequency of discharge of MnPN sleep-related neurons in quiet waking determined from the previous data (Suntsova et al., 2002).

The effective current spread around the tips of bipolar side-by-side electrodes has not been estimated. However, it is likely to be less than or at the most comparable with the spread from a tip of a monopolar electrode, which was estimated as the square root of the current divided by the square root of the excitability constant (Tehovnik et al., 2006). Applying this equation, monopolar stimulation with parameters used in our study would be expected to activate the most excitable neurons within 0.6 $\mathrm{mm}$ radius. The effective current spread from a monopolar electrode has been estimated as 250-500 $\mu \mathrm{m}$ based on single-cell recordings or using behavioral methods (Wise, 1972; Bagshaw and Evans, 1976; Tehovnik et al., 2006). Compared with some of these studies, we used larger electrode tips, which could result in a smaller effective current spread (Follett and Mann, 1986). This is supported by our finding that $150-200 \mu \mathrm{m}$ shifts in electrode position from the MnPN margins in mediolateral or dorsocaudal directions led to disappearance of EEG-synchronizing effect of highfrequency (100-200 pulses/s) MnPN stimulation and recruiting responses evoked by low-frequency MnPN stimulation.

The main advantage of the method of electrical stimulation is its high temporal resolution allowing the distinction of antidromic, monosynaptic and polysynaptic responses. A limitation is lack of selectivity for neurons. Possible excitation of axonal terminals and fibers of passage in addition to neuronal cell bodies results in uncertainty regarding the origin of obtained responses. To overcome this problem, we also applied local chemical activation and inhibition of neuronal cell bodies and dendrites within the MnPN. This method, however, has lower temporal precision and permits assessment of only relatively long-term tonic influences of MnPN afferents.

Reverse microdialysis. MnPN cellular activity was manipulated chemically using microdialytic application of $\mathrm{L}$-glutamate, the $\mathrm{GABA}_{\mathrm{A}}$ receptor antagonist bicuculline methiodide, and the $\mathrm{GABA}_{\mathrm{A}}$ receptor agonist muscimol (all from Sigma, St. Louis, MO) to excite, disinhibit, and inhibit the MnPN neurons, respectively.

The microdialysis probe (cuprophane semipermeable membrane length, $1 \mathrm{~mm}$; outer diameter, $0.24 \mathrm{~mm}$; molecular weight cutoff, 6000 Da; CMA/11; CMA Microdialysis, North Chelmsford, MA) was inserted into the implanted guide cannula $24 \mathrm{~h}$ before starting an experiment. The tip of the probe extended $3 \mathrm{~mm}$ beyond the tip of the guide cannula. The positioning of the probe was chosen to minimize damage to the nucleus (Fig. $1 D$ ). The tip of the probe (covered with glue for $0.3-0.5 \mathrm{~mm}$ ) was placed within the most rostral part of the MnPN. The open part of the 
microdialysis membrane was in contact with a dorsal surface of the nucleus.

The probe was continuously perfused at a flow rate of $2.0 \mu \mathrm{l} / \mathrm{min}$ with filtered artificial CSF (aCSF) containing the following (in $\mathrm{mm}$ ): $145 \mathrm{NaCl}, 2.7 \mathrm{KCl}, 1.3 \mathrm{MgSO}_{4}, 1.2 \mathrm{CaCl}_{2}$, and 2 $\mathrm{Na}_{2} \mathrm{HPO}_{4}, \mathrm{pH}$ 7.2. All drugs were dissolved in this solution. Gastight Bee Stinger syringes were filled with perfusates and mounted on Baby Bee Syringe Pumps connected to Bee Hive Pump controllers (Bioanalytical Systems, West Lafayette, IN). To change syringes during microdialysis without interrupting flow, a liquid switch (UniSwitch; Bioanalytical Systems) was used. After delivery of substances, the perfusion solution was switched back to aCSF and the recording continued for another 45-90 min or until the discharge rate was at baseline levels.

To examine the effects of MnPN chemical activation and disinhibition on $\mathrm{PF} / \mathrm{LH}$ neuronal activity, $1 \mathrm{~mm}$ L-glutamate, $50 \mu \mathrm{m}$ bicuculline, and $50 \mu \mathrm{M}$ muscimol concentrations have been chosen in preliminary experiments. These concentrations, on one hand, were below the threshold for induction of EEG and behavioral manifestations of absence-like seizures but, on the other hand, were shown to be effective to modulate behavior, neuronal discharge, c-Fos immunoreactivity, and neurotransmitter release while applied by reverse microdialysis into the other structures (Karreman and Moghaddam, 1996; Materi and Semba, 2001; West et al., 2002; Satoh et al., 2004; Alam et al., 2005a). Excesses of either L-glutamate or bicuculline can potentially inactivate instead of

G

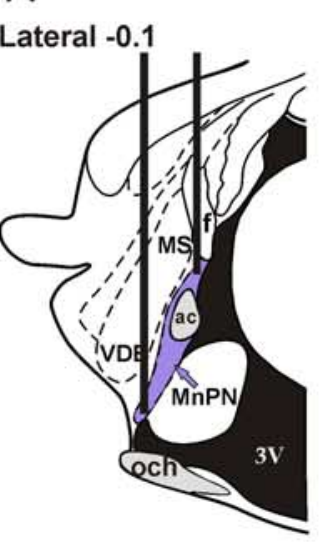

$D$

\section{Lateral -0.1}
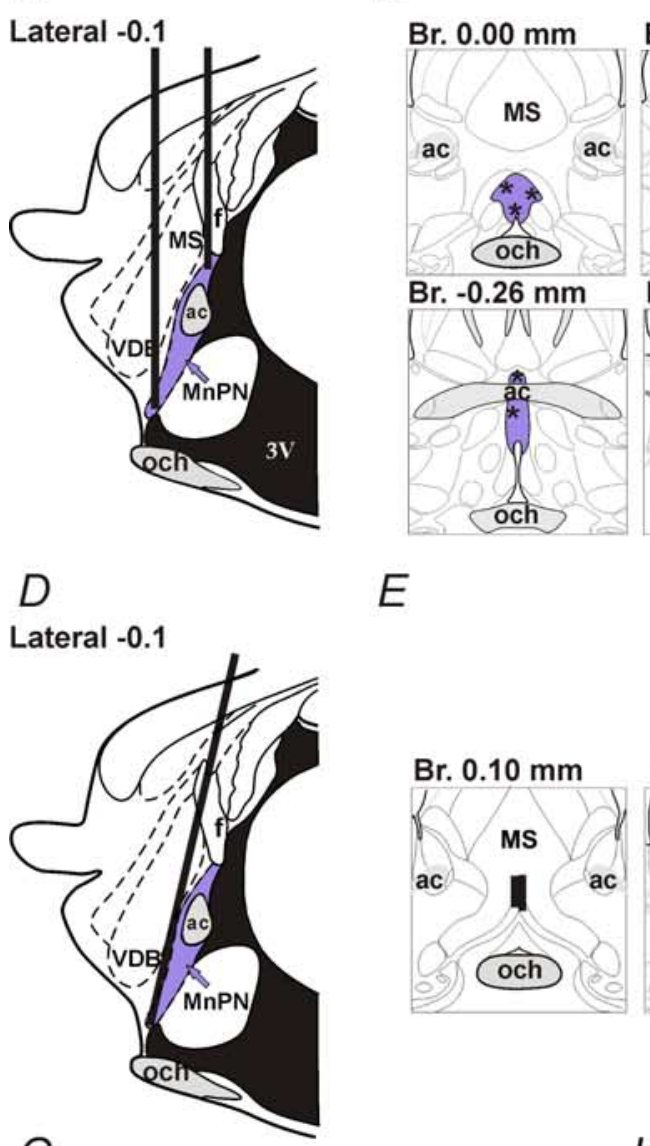

E
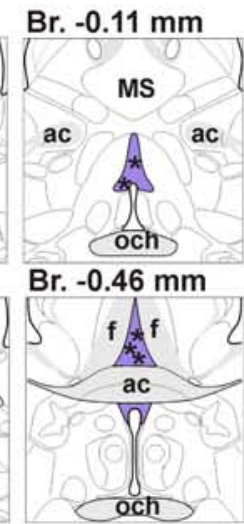

F
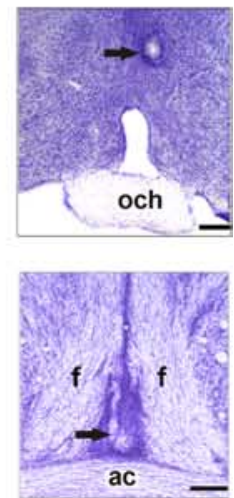

Br. $0.00 \mathrm{~mm}$
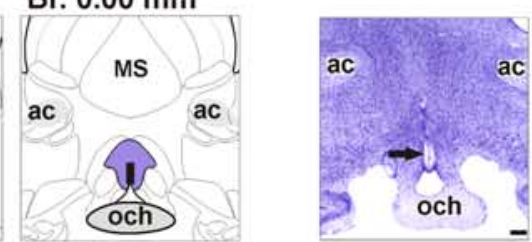

$\rightarrow$

Figure 1. Anatomical localization of stimulating electrodes, microdialysis probes, and recorded neurons. $\boldsymbol{A}, \boldsymbol{D}$, Schematic drawing showing targeted placement of stimulating electrodes $(\boldsymbol{A})$ and microdialysis probes $(\boldsymbol{D})$ at sagittal section of the rat brain. $\boldsymbol{B}, \boldsymbol{E}$, Histologically verified locations of the tips of stimulating electrodes ( $\boldsymbol{B}$, asterisks) and microdialysis probes ( $\boldsymbol{E}$, vertical bars) plotted on diagrams of coronal sections. The locations of the tips of stimulating electrodes within rostral and caudal MnPN in $\boldsymbol{B}$ are shown on the top and bottom panels, respectively. The MnPN is highlighted with blue color. $\boldsymbol{C}, \boldsymbol{F}$, Photomicrographs of Nissl-stained sections showing the locations of stimulating electrodes and microdialysis probes. The arrows indicate the sites of electrolytic lesions within the rostral ( $\boldsymbol{C}$, top) and caudal ( $\boldsymbol{C}$, bottom) MnPN and track of the tip of microdialysis probe within the rostral $\operatorname{MnPN}(\boldsymbol{F})$. Scale bar, $250 \mu \mathrm{m} . \mathbf{G}, \boldsymbol{H}$, Locations of neurons with different sleep-wake discharge patterns recorded within the $\mathrm{PF} / \mathrm{LH}$ during experiments with electrical stimulation $(\boldsymbol{G})$ and microdialytic perfusion $(\boldsymbol{H})$ of the MnPN. For better visualization, AW/REM sleep-related neurons (circles) are shown on the left side and AW-related (triangles), NREM/REM sleeprelated (diamonds), REM sleep-related (rectangles), and state-indifferent (asterisks) units are shown on the right side of the drawings. The perifornical area is outlined with brown. I, Photomicrographs of stained for hypocretin-1 histological sections showing the locations of microwire tracks (arrows) within lateral (1) and medial (2) parts hypocretinimmunoreactive neuronal field. Scale bar, $50 \mu \mathrm{m}$. MS, Medial septal nucleus; ac, anterior commissure; och, optic chiasm; $\mathrm{f}$, fornix; VDB, nucleus of the vertical limb of the diagonal band; $3 \mathrm{~V}$, third ventricle; $\mathrm{Br}$., bregma.

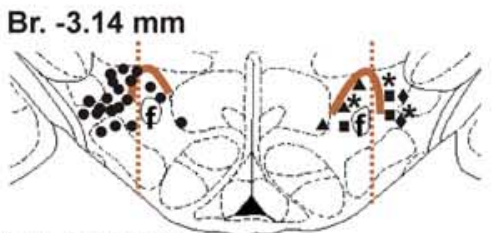

Br. $-3.30 \mathrm{~mm}$

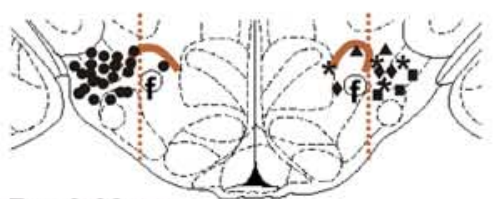

Br. $-3.60 \mathrm{~mm}$

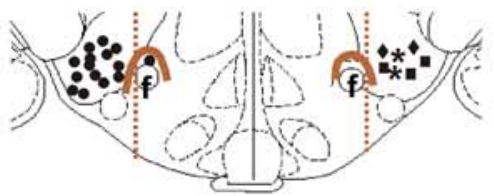

l

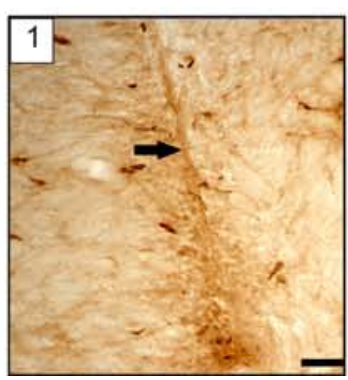

$H$

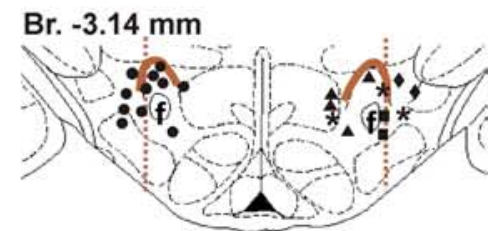

Br. $-3.30 \mathrm{~mm}$
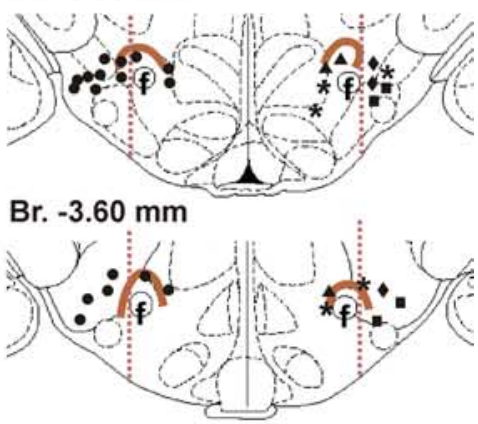

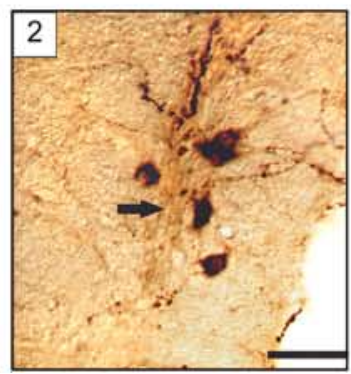


stimulate MnPN neurons because of depolarization block. However, significantly higher concentrations of these drugs have been used previously to physiologically activate brain regions (Georges and Aston-Jones, 2001; Zhang and Fogel, 2002; Hanamori, 2003; Puig et al., 2003). The concentration of bicuculline used in our study $(0.025 \mu \mathrm{g} / \mu \mathrm{l}$ in the perfusion fluid and $\sim 10$ times less in the tissue) was much lower than reported to produce a depolarization blockage $(0.75 \mu \mathrm{g} / \mu \mathrm{l})$ in microinjection experiments (Perier et al., 2002). In addition, in our preliminary studies, we never observed inhibitory responses of preoptic area neurons to L-glutamate and bicuculline locally microdialyzed at concentrations used in this study. These preliminary experiments and our previous data (Alam et al., 2005a) based on c-Fos analysis allowed us to estimate the effective spread of drugs delivered by reverse microdialysis $(0.5-0.75$ $\mathrm{mm}$ around the probe).

Data analysis. To determine the state-related changes in discharge of the recorded cells, the mean firing rates were calculated for 10 15-60 s artifact-free periods of AW, QW, NREM, and REM sleep, which were identified on the basis of EEG and EMG parameters using standard criteria (Timo-Iaria et al., 1970). Recorded cells were classified into groups with different sleep-wake firing rate profiles based on the results of a $\mathrm{K}$-means cluster analysis followed by evaluation of state-relatedness for each member of the cluster (Suntsova et al., 2002). One-way ANOVA followed by Tukey's honestly significant difference (HSD) post hoc test was used to examine the interstate differences in the mean firing rates of individual neurons and groups of cells with different sleep-wake discharge profiles.

The orthodromic responses of PF/LH neurons evoked by MnPN stimulation were characterized by measuring the onset latency and duration of stimulation-induced effects from peristimulus time histograms (PSTHs). To generate PSTHs, at least 80 trials of single-pulse stimulation performed during AW were selected. The trials were divided into $1 \mathrm{~ms}$ bins, and action potentials occurring within each bin were summed over all stimulation trials. Significant excitatory or inhibitory poststimulus neuronal responses were identified in those bins whose counts were $>2$ SDs above or below, respectively, the baseline mean (averaged over a prestimulus period of $200 \mathrm{~ms}$ ). For slowly firing cells, inhibition was defined by a $>50 \%$ decrease in the firing rate with respect to the prestimulus value. The neuronal response onset latency and offset were defined as the first of five consecutive bins meeting the response criterion and no longer meeting the criterion, respectively. Five millisecond windows allowed us to identify both short- and long-duration responses.

Given that conduction time from the MnPN to the PF/LH is unknown, neuronal responses with onset latencies less than $\sim 15$ ms potentially could be considered as antidromic or monosynaptic, taking into account possibility of low conduction velocity (Stocker and Toney, 2005) and slow synaptic transmission. Short-latency excitatory responses were operationally defined as monosynaptic if latency jitter (SD of the time from the beginning of the stimulus artifact to the beginning of the first evoked spike) was $<0.5 \mathrm{~ms}$. Antidromic criteria included the ability to follow single pulses with a constant latency $(<0.1 \mathrm{~ms}$ latency jitter $)$ and to follow high-frequency stimulus trains at 100-200 pulses/s.

To estimate the effects of MnPN train stimulation on the firing rate of PF/LH neurons, PSTHs ( $0.1 \mathrm{~s}$ bin width; 250 bins; summation of at least 30 stimulation trials) and raster displays were generated, which provided graphic representation of neuronal activity occurring from $5 \mathrm{~s}$ before to $15 \mathrm{~s}$ after the end of the train stimulation. To generate PSTHs, pulses initiating trains of stimuli were used as triggers. The mean firing rates were calculated for $5 \mathrm{~s}$ epochs before and during stimulation as well as for three consecutive epochs that followed the stimulation. These measurements were done for each individual trial and for averaged trials. The statistical significance of changes in the firing rate for each individual neuron and for subsets of the cells was determined using one-way repeated-measures ANOVA with time as a repeated measure followed by Tukey's HSD post hoc test.

To quantify the sleep-wake parameters during baseline conditions and chemical treatments of the MnPN, EEG and EMG recordings were scored on the basis of the predominant state within each $10 \mathrm{~s}$ epoch during $1 \mathrm{~h}$ of predrug aCSF perfusion and during $1 \mathrm{~h}$ period starting from the beginning of drug application. The percentages of time spent in AW, QW, NREM, and REM sleep were calculated per hour.

To quantify the effect of chemical manipulations of the MnPN on the discharge of the $\mathrm{PF} / \mathrm{LH}$ neurons, mean firing rates were calculated for sleep-wake states during baseline aCSF perfusion and drug administration. Average firing rates obtained during different sleep-wake states before and during drug application were compared with two-way repeated-measures ANOVA with two within-subjects factors. One factor was defined as a sleep-wake state with four levels (AW, QW, NREM, and REM sleep). The other factor was drug treatment with two levels (aCSF perfusion and drug administration). In cases of violation of sphericity assumption (Mauchley sphericity test), to avoid erroneous results of univariate ANOVA, a multivariate approach was applied to test the significance of univariate repeated-measures factors with more than two levels (Wilk's multivariate test). In presence of a significant main effect, post hoc comparisons were done using Tukey's HSD test.

Results are expressed throughout as mean \pm SEM. The level of significance was set at $p<0.05$.

Histology. At the end of a recording session, under deep anesthesia (pentobarbital; $100 \mathrm{mg} / \mathrm{kg}$, i.p.), microlesions were made at the tip of microwires (20 $\mu \mathrm{A}$ anodal direct current; $15-20 \mathrm{~s}$ ) at the most ventral recorded site. After injection with heparin (500 U, i.p.), animals were perfused transcardially with $30-50 \mathrm{ml}$ of $0.1 \mathrm{~m}$ phosphate buffer, $\mathrm{pH} 7.2$, followed by $300 \mathrm{ml}$ of $4 \%$ paraformaldehyde in phosphate buffer containing $15 \%$ saturated picric acid solution, $100 \mathrm{ml}$ of $10 \%$ sucrose, and finally $100 \mathrm{ml}$ of $30 \%$ sucrose in phosphate buffer. The brains were removed and equilibrated in $30 \%$ sucrose. Serial coronal sections $(40 \mu \mathrm{m})$ were stained for Nissl (cresyl violet) to verify the position of the stimulating electrodes. To verify the position of microwire tracks within the hypocretin neuronal field, sections through the PF/LH were immunostained for hypocretin-1 as described previously (Alam et al., 2002).

Reconstructions of tracts of stimulation electrodes, microdialysis probes, and microwires were made with the aid of Neurolucida imaging system (MicroBrightField, Colchester, VT) guided by the rat brain atlases of Paxinos and Watson (1998) and Swanson (1998) for PF/LH area and the MnPN, respectively. According to reconstructions, stimulating electrodes were correctly positioned in five rats (Fig. $1 B, C$ ). From these animals, 87 cells, recorded within hypocretin-immunoreactive neuronal field with signal-to-noise ratio $\geq 3$ (Fig. $1 G$ ), were examined for their sleep-wake discharge patterns and responses to the MnPN electrical stimulation. The vast majority $(85 \% ; n=74)$ of these neurons were recorded lateral to the fornix and were considered to be in the LH. The rest of the cells were recorded dorsal or medial to the fornix, within the perifornical and dorsomedial hypothalamic nucleus. Localizations of both microdialysis probes (Fig. $1 E, F$ ) and microwires (Fig. $1 H$ ) within the targets were histologically confirmed in three rats. Responses of 54 $\mathrm{PF} / \mathrm{LH}$ neurons with identified sleep-wake discharge profiles to chemical stimulation and/or inhibition of the MnPN were analyzed.

\section{Results}

\section{EEG responses to $\mathrm{MnPN}$ electrical stimulation}

The effects of the MnPN single-pulse and train stimulation on $\mathrm{PF} / \mathrm{LH}$ neuronal activity were studied during active waking. Five second train stimulation of the $\mathrm{MnPN}$ (200 $\mu \mathrm{s}, 100 \mu \mathrm{A}$ square pulses with $150 \mathrm{~ms}$ period) evoked rhythmic activity resembling recruiting responses or spindle-like activity in combination with high-amplitude $\delta$ waves. Trains of high-frequency stimuli (100200 pulses/s) also triggered EEG synchronization within the frequency range of sleep spindles. Single stimulus pulses of the same duration and intensity at frequency 0.5 pulses/s failed to induce EEG synchronization in AW. However, in QW and NREM sleep, stimulation with these parameters evoked slow (180-300 ms) waves followed by rhythmic afterdischarges (series of waves that occurred at $10-25 \mathrm{~Hz}$ and lasted up to $1.5 \mathrm{~s}$ ). 
Table 1. Summary of electrophysiological responses of PF/LH neurons to a single-pulse MnPN stimulation

\begin{tabular}{|c|c|c|c|c|c|c|c|c|c|c|}
\hline \multirow[b]{3}{*}{ Sleep-wake discharge profile } & \multicolumn{6}{|c|}{ Initial response } & \multicolumn{4}{|c|}{ Second response } \\
\hline & \multicolumn{3}{|l|}{ Inhibition } & \multicolumn{3}{|c|}{ Excitation } & \multicolumn{2}{|c|}{ Excitation } & \multicolumn{2}{|c|}{ Inhibition } \\
\hline & $\begin{array}{l}\text { Number } \\
\text { of cells }\end{array}$ & $\begin{array}{l}\text { Latency } \\
\text { (ms) }\end{array}$ & Duration (ms) & $\begin{array}{l}\text { Number } \\
\text { of cells }\end{array}$ & $\begin{array}{l}\text { Latency } \\
\text { (ms) }\end{array}$ & $\begin{array}{l}\text { Duration } \\
\text { (ms) }\end{array}$ & $\begin{array}{l}\text { Number } \\
\text { of cells }\end{array}$ & $\begin{array}{l}\text { Duration } \\
\text { (ms) }\end{array}$ & $\begin{array}{l}\text { Number } \\
\text { of cells }\end{array}$ & $\begin{array}{l}\text { Duration } \\
\text { (ms) }\end{array}$ \\
\hline AW/REM sleep-related with SPFM $(n=41)$ & 31 & $6.5 \pm 0.9$ & $87.1 \pm 7.7$ & & & & 10 & $44.2 \pm 5.9$ & & \\
\hline AW/REM sleep-related with MFM $(n=16)$ & 6 & $24.0 \pm 1.1$ & $119.3 \pm 25.5$ & 8 & $3.6 \pm 0.4$ & $5.3 \pm 1.6$ & & & 8 & $74.6 \pm 14.4$ \\
\hline AW-related $(n=5)$ & 4 & $6.8 \pm 2.5$ & $82.3 \pm 22.1$ & & & & & & & \\
\hline NREM/REM sleep-related $(n=9)$ & & & & 9 & $9.0 \pm 1.8$ & $9.1 \pm 1.8$ & & & 7 & 60.6. \pm 11.2 \\
\hline REM sleep-related $(n=9)$ & & & & 7 & $7.4 \pm 1.2$ & $11.4 \pm 3.3$ & & & 3 & $49.7 \pm 8.1$ \\
\hline State-indifferent $(n=7)$ & & & & 4 & $21.0 \pm 1.9$ & $30.5 \pm 8.7$ & & & & \\
\hline
\end{tabular}

\section{PF/LH neurons: sleep-wake discharge patterns and responses} to MnPN electrical stimulation

The electrophysiological responses of $87 \mathrm{PF} / \mathrm{LH}$ neurons were analyzed.

In agreement with previous $\mathrm{PF} / \mathrm{LH}$ unit activity studies (Alam et al., 2002; Koyama et al., 2003), the examined cells were heterogeneous in terms of their sleep-wake discharge profiles. Based on the results of cluster analysis followed by evaluation of staterelatedness for each member of the cluster, PF/LH cells were subdivided into five groups designated in accordance with the state(s) in which unit discharge was the highest, namely: AW/REM sleep-related, AW-related, NREM/REM sleep-related, REM sleep-related, and state-indifferent neurons.

Single-pulse stimulation of the MnPN performed during AW elicited discharge changes in 69 of the $87 \mathrm{PF} / \mathrm{LH}$ cells $(79.3 \%)$. No cells were activated antidromically. Although the predominant $\mathrm{MnPN}$-induced transynaptic effect was inhibitory, neurons with different sleep-wake discharge profiles exhibited different reactions to stimulation. Characteristics of these responses are summarized in Table 1.

\section{AW/REM sleep-related neurons}

Sleep-wake discharge pattern. Fifty-seven PF/LH cells (65.5\%) fired at higher rates during AW and REM sleep compared with QW and NREM sleep. The interstate differences in the mean firing rate of these cells as a group and sleep-wake discharge profiles of individual units are shown in Figure 2, $A$ and $B$, respectively.

The majority ( $n=41 ; 71.9 \%)$ of AW/REM sleep-related cells exhibited a single-pulse firing mode (SPFM) across all sleepwake states (Fig. 3A). The rest of AW/REM sleep-related units $(n=16 ; 28.1 \%)$ generated single pulses during waking and REM sleep and a combination of single pulses and high-frequency (400-900 pulses/s) burst discharges during NREM sleep. These cells were identified within the PF/LH for the first time and were designated as mixed firing mode (MFM) neurons (Fig. 3C). An ability of PF/LH neurons to generate bursts during NREM sleep is compatible with the findings that some $\mathrm{LH}$ neurons express a low-voltage-activated calcium current (Fan et al., 2000) and receive inhibitory inputs from the reticular thalamus (Barone et al., 1994). The percentage of AW/REM sleep-related cells was higher among the neurons recorded within $\mathrm{LH}(70.3 \%)$ than among the neurons recorded within the medial part of hypocretinimmunoreactive neuronal field (38.5\%). All cells with MFM were found within the LH.

Responses to stimulation. Forty-five AW/REM sleep-related cells (79\%) responded to a single-pulse $\mathrm{MnPN}$ stimulation. The responses fell into three categories: (1) a pure inhibition, (2) an initial inhibition followed by excitation, and (3) an initial excita- tion followed by inhibition (Table 1). The percentages and representative examples of these responses are shown in Figure 2, $C$ and $D-F$, respectively.

Exclusively inhibitory reactions or initial inhibitions were found in 37 cells ( $82 \%$ of responsive units). The vast majority of these responders were SPFM neurons $(n=31)$. The overall mean response latency and duration of exclusively and initially inhibitory responses are shown in Table 1.

Twenty-seven AW/REM sleep-related cells (21 SPFM neurons and 6 MFM cells) exhibited pure inhibitory responses (Figs. 2D, $3 B)$. K-mean clustering analysis showed existence of three clusters of units $\left(n_{1}=10 ; n_{2}=11 ; n_{3}=6\right)$ differing in latency of response $(2.0 \pm 0.2,11.5 \pm 0.9$, and $24.0 \pm 1.1 \mathrm{~ms}$, respectively). The first two clusters included SPFM neurons, whereas the longest latencies were found in MFM cells, which constituted the third cluster (Fig. 2G). Overall mean onset latency and duration of pure inhibitory responses were $10.4 \pm 1.7$ and $105.1 \pm 9.1 \mathrm{~ms}$, respectively.

Biphasic inhibitory-excitatory responses (Fig. 2E) were found only in SPFM cells $(n=10 ; 18 \%)$. These neurons were grouped into two clusters $\left(n_{1}=4 ; n_{2}=6\right)$ with different latency of initial inhibitory response $(1.5 \pm 0.3$ and $10.0 \pm 0.7 \mathrm{~ms}$, respectively) (Fig. $2 H$ ). The period of discharge reduction lasted for $57.7 \pm 8.6 \mathrm{~ms}$ and was shorter $(p<0.01$, Student's $t$ test $)$ than in purely inhibited SPFM cells $(101.1 \pm 9.3)$. The mean duration of postinhibitory excitation was $44.2 \pm 5.9 \mathrm{~ms}$.

Biphasic excitatory-inhibitory responses were found exclusively in MFM neurons $(n=8 ; 14 \%)$ (Figs. $2 F, 3 D)$. They were excited with a latency ranging from 2 to $5 \mathrm{~ms}$ (Fig. $2 \mathrm{I}$ ). The mean latency and duration of both excitatory and inhibitory components of these responses are shown in Table 1.

During $5 \mathrm{~s}$ MnPN train stimulation, the vast majority (84.2\%) of AW/REM sleep-related cells significantly ( $p<0.05$, Tukey's HSD post hoc test) decreased their firing rates to $7.1-74.8 \%$ of prestimulation firing. No neurons were facilitated. The overall mean firing rate of responding AW/REM sleep-related cells was reduced by $42.7 \%$ during stimulation ( $p<0.001$, Tukey's HSD post hoc test). Discharge remained decreased by $31.8 \%$ for $5 \mathrm{~s}$ after the end of stimulus trains $(p<0.001)$ and by $15.4 \%$ during a subsequent $5 \mathrm{~s}$ epoch $(p<0.05)$ (Fig. $2 J)$. The group of cells inhibited by train stimulation included both the neurons reactive to single-pulse stimulation and units unresponsive to single stimuli (Fig. $2 K, L$ ). In the latter case, it is likely that temporal summation of postsynaptic potentials was needed to suppress discharge of the target neuron.

\section{AW-related neurons}

Sleep-wake discharge pattern. Five PF/LH cells (5.8\%) exhibited maximum firing rates during AW. The interstate differences in 
$A$

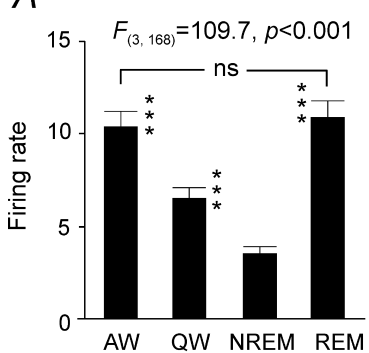

$D$

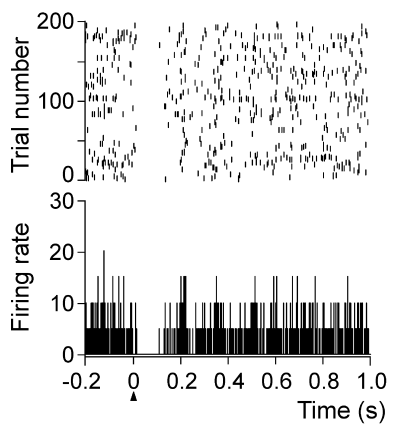

G

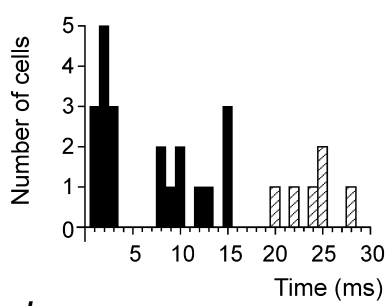

$J$

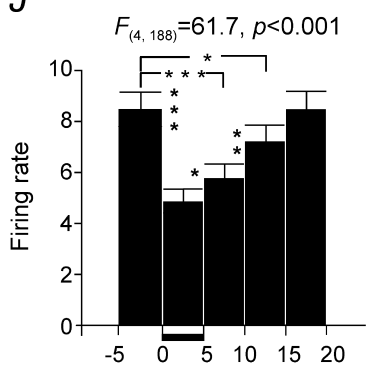

$B$

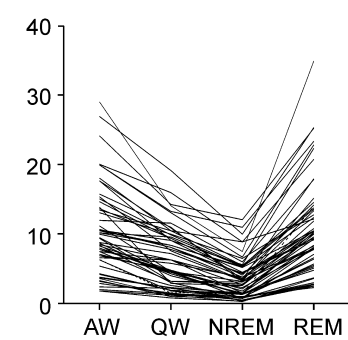

$E$
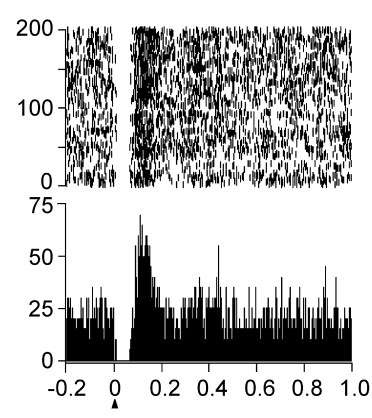

$H$
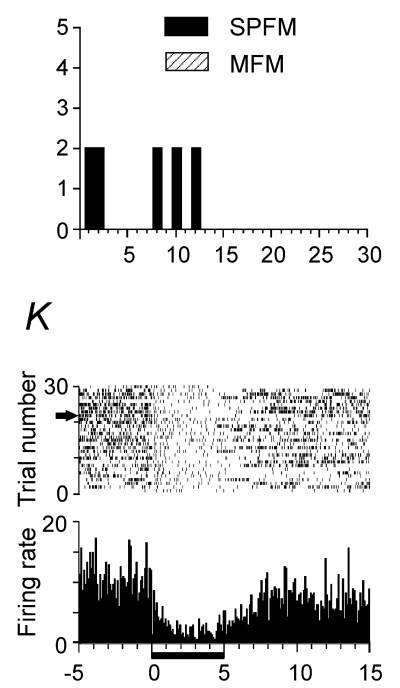

C

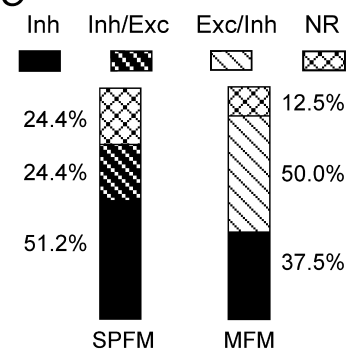

$F$
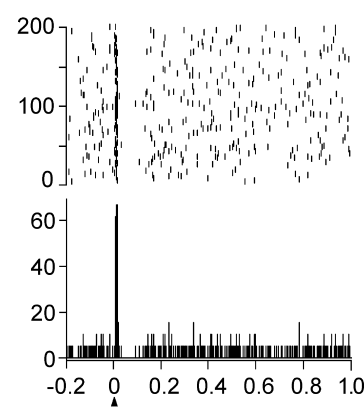

I
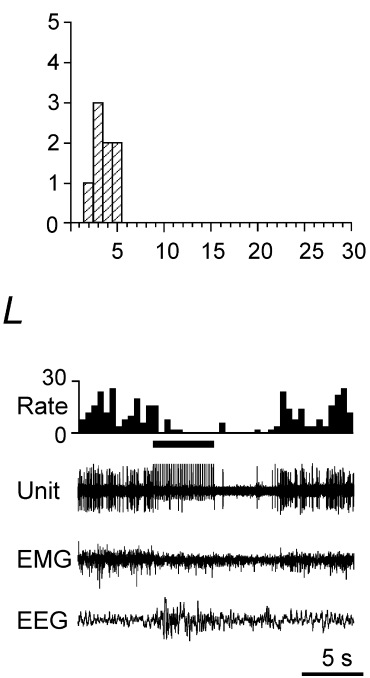

Figure 2. Summary of discharge characteristics of AW/REM sleep-related PF/LH neurons and their responses to MnPN electrical stimulation. $A$, Group mean \pm SEM discharge rates (spikes/second) of AW/REM sleep-related cells across sleep-wake states. The mean firing rate in AW and REM sleep was significantly higher than in QW and NREM sleep (one-way repeated-measures ANOVA followed by Tukey's HSD test). B, Mean discharge rates of individual neurons. C, Percentages of different types of responses to MnPN electrical stimulation exhibited by neurons with SPFM and MFM. Note the low proportion of nonresponsive (NR) units and the high percentage of cells exhibiting pure inhibitory responses (Inh) in both SPFM and MFM subsets of neurons. The rest of SPFM neurons exhibited inhibitory/excitatory responses (Inh/Exc), whereas the remainder of MFM neurons responded with initial excitation always followed by inhibition (Exc/Inh). D-F, Representative examples of raster plots (top panel) and PSTHs (bottom panel) corresponding to an $\operatorname{lnh}(\boldsymbol{D}), \operatorname{lnh} / \operatorname{Exc}(\boldsymbol{E})$, and Exc/Inh $(\boldsymbol{F})$ responses after single-pulse electrical stimulation of the MnPN. For all PSTHs here and in subsequent figures, electrical pulses (200 $\mu \mathrm{s} ; 100 \mu \mathrm{A})$ were applied at time 0 (arrowheads), and bin width was $1 \mathrm{~ms}$. The scale on the $y$-axis is in spikes/second. Raster display shows the occurrence of spikes for each trial accumulated in the PSTH. The $y$-axis in the raster plot shows the number of trials. $\mathbf{G}-\mathbf{I}$, Histograms showing distributions of onset latencies for pure inhibitory $(\boldsymbol{G})$, initially inhibitory $(\boldsymbol{H})$, and initially excitatory $(\boldsymbol{I})$ responses. Note a substantial proportion of short-latency responses. $J-L$, Responses of AW/REM sleep-related units to train stimulation of the MnPN. J, Group mean \pm SEM firing rate of 48 units calculated for five consecutive $5 \mathrm{~s}$ epochs starting with the epoch immediately preceding stimulation period. During stimulation $200 \mu \mathrm{s}, 100 \mu \mathrm{A}$ pulses were applied to the MnPN with $150 \mathrm{~ms}$ period for $5 \mathrm{~s}$ (horizontal bar next to $x$-axis). Note that the group mean firing rate significantly decreased during stimulation and continued to be reduced for $10 \mathrm{~s}$ after completion of stimulation. $\boldsymbol{K}$, Inhibition by train stimulation of a neuron unresponsive to single-pulse stimulation. PSTH ( $0.1 \mathrm{~s}$ bin width, summation of 30 stimulation trials) and raster display provide graphic representation of activity of this cell occurring from $5 \mathrm{~s}$ before the beginning to $10 \mathrm{~s}$ after the end of the train stimulation. $L$, Firing rate histogram, unit activity, EMG, and EEG during a single stimulation trial marked by the arrow in $\boldsymbol{K}^{*} p<0.05 ;{ }^{* *} p<0.01 ;{ }^{* * *} p<0.001$; ns, nonsignificant.

the mean firing rate of these cells as a group and sleep-wake discharge profiles of individual units are shown in Figure 4, $A$ and $B$, respectively. All AW-related neurons exhibited a single-pulse firing mode in each stage of the sleep-wake cycle.

Four AW-related cells were recorded dorsal or medial to the fornix (Fig. $1 G$ ). Their percentage within this region was $30.8 \%$, which is comparable with that previously reported (Alam et al., 2002). Lateral to the fornix, only one of 74 recorded neurons $(1.4 \%)$ was AW-related. Hypocretin cells exhibit an AW-related discharge profile (Lee et al., 2005; Mileykovskiy et al., 2005). The low percentage of AW-related neurons within the lateral division of hypocretin field implies that lateral hypocretin cells are either selectively active during specific waking behaviors underrepresented in our experimental conditions or have a different sleep-wake discharge profile.

Responses to stimulation. Four AWrelated neurons responded to a singlepulse electrical stimulation of the MnPN with pure inhibition (Fig. $4 C, D, H$ ). Two cells responded with 2 and 3 ms latency, and the other two cells were inhibited 10 and $12 \mathrm{~ms}$ after stimulus onset (Fig. $4 E$ ). The mean onset latency and duration of responses are shown in Table 1. All AWrelated units were inhibited during MnPN train stimulation. The firing rates decreased to $26.4-64.0 \%$ of baseline firing. The overall mean firing rate of $\mathrm{AW}$-related units decreased by 58.3\% ( $p<0.001$, Tukey's HSD post hoc test) during stimulation and remained reduced during two consecutive $5 \mathrm{~s}$ epochs subsequent to stimulation period by $51.0 \%(p<0.001)$ and $30.1 \%(p<0.05)$ compared with prestimulation firing (Fig. $4 F$ ).

\section{Sleep-related neurons}

Sleep-wake discharge patterns. Eighteen PF/LH neurons (20.7\%) were sleeprelated. These cells were identified as either NREM/REM sleep- or REM sleeprelated, depending on the sleep state(s) during which they exhibited elevated discharge compared with waking.

NREM/REM sleep-related neurons ( $n=9 ; 10.3 \%)$ were for the first time identified within the PF/LH. They increased their discharge during both NREM and REM sleep compared with waking states. REM sleep-related neurons ( $n=9$; $10.3 \%$ ) increased firing rates during REM sleep compared with waking states and NREM sleep. Activation of cells occurred 8-46 s before REM sleep onset. The interstate differences in the group mean firing 
A

SPFM neuron

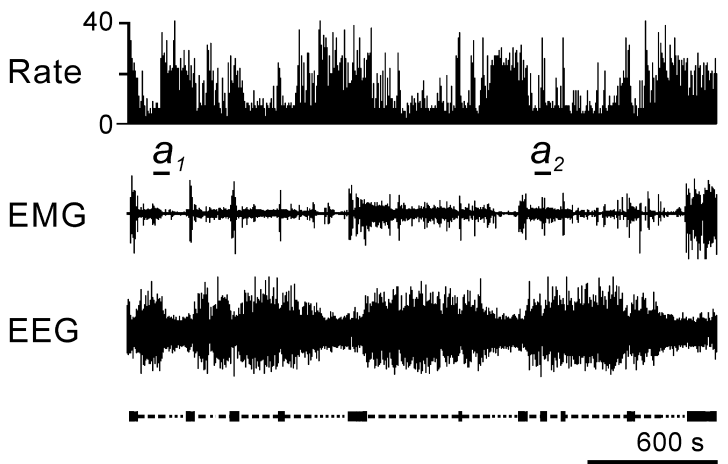

$a_{1}$

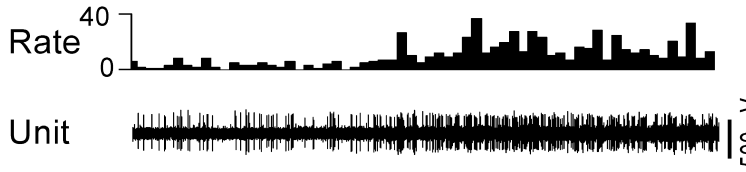

EMG

EEG

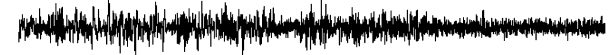

C

MFM neuron
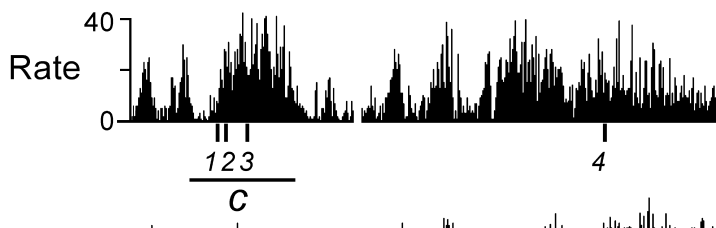

EMG

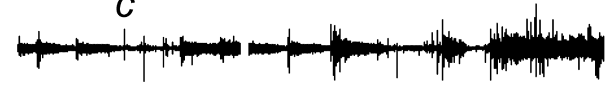

EEG

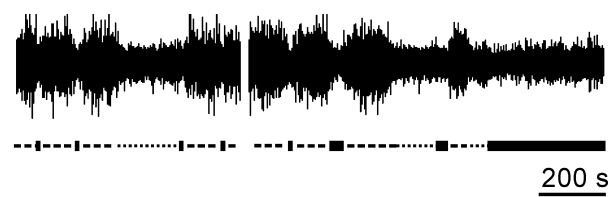

C

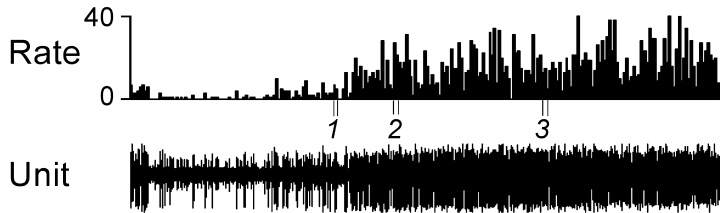

EMG

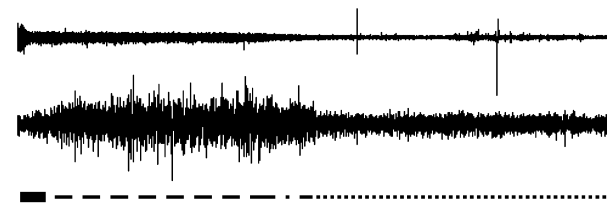

$\underline{20 \mathrm{~s}}$
B
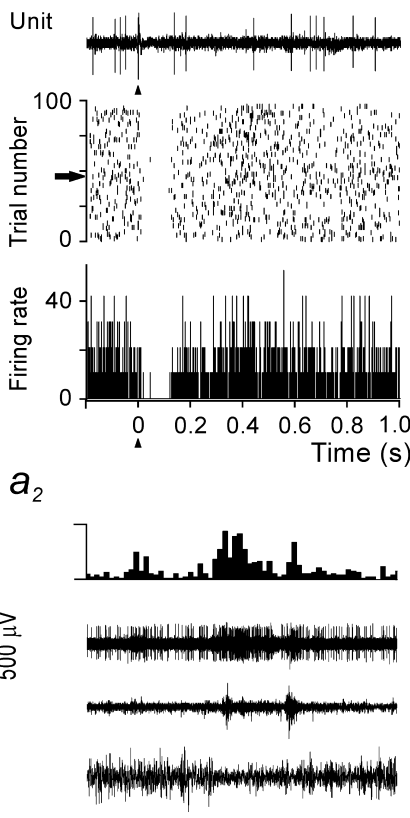

$\underline{5 s}$

$D$

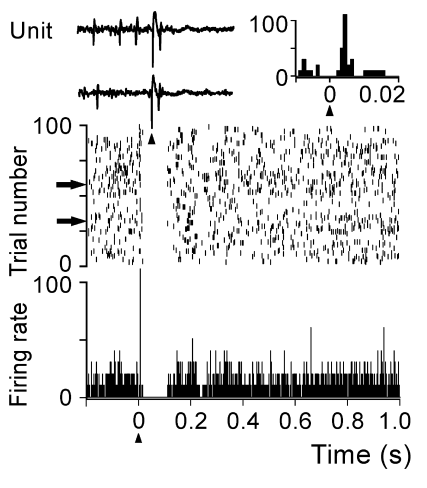

Time (s)

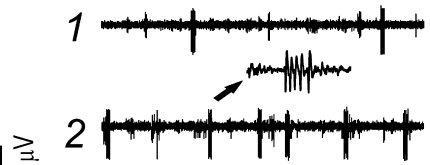

킁
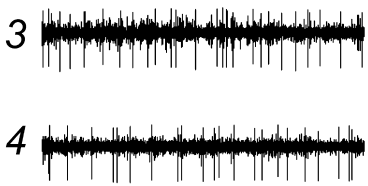

$0.5 \mathrm{~s}$

Figure 3. Representative examples of the responses evoked in AW/REM sleep-related PF/LH neurons with SPFM and MFM by MnPN electrical stimulation. $A$, The discharge of SPFM cell across the sleep-waking cycle. Here and in subsequent figures showing polygraphic recordings that illustrate the sleep-wake discharge patterns of $\mathrm{PF} / \mathrm{LH}$ neurons, the firing rate histogram (Rate) electromyogram (EMG), and electroencephalogram (EEG) are displayed. The scale on the $y$-axis in the firing rate histograms is in spikes/second. The sleep-wake states (wakefulness, NREM sleep, transition from NREM to REM sleep, REM sleep) are indicated under the EEG tracings using thick solid, dashed, dot-dash, and dotted lines, respectively. Extracellularly recorded unit activity (Unit) is shown on expanded tracing from the sections marked by horizontal bars $\left(\boldsymbol{a}_{1}, \boldsymbol{a}_{2}\right)$. Note that the cell belongs to the subset of SPFM cells $(n=15)$ that dramatically increased their discharge $8-23$ s before REM sleep onset $\left(\boldsymbol{a}_{1}\right)$ and almost simultaneously

rates of sleep-related cells and sleep-wake discharge profiles of individual units are shown in Figure 5, $A$ and $B$, respectively.

All sleep-related neurons exhibited a tonic firing mode across sleep-wake states.

The percentages of sleep-related cells among neurons recorded medial and lateral to the fornix were comparable.

Responses to stimulation. All NREM/ REM sleep-related cell and seven of nine REM sleep-related neurons were responsive to the MnPN single-pulse stimulation exhibiting either exclusively excitatory or excitatory-inhibitory responses (Fig. 5C). Table 1 shows the overall mean latency and duration of excitatory responses and the mean duration of postexcitatory inhibitions calculated separately for NREM/ REM sleep- and REM sleep-related units. None of these parameters differs significantly between subsets of sleep-related cells.

Pure orthodromic excitations were found in two NREM/REM sleep-related neurons (Figs. 5D, 6B) and in four REM sleep-related cells with latencies ranging from 2 to $18 \mathrm{~ms}$. Seven NREM/REM sleepand three REM sleep-related neurons (Fig. $5 E$ ) were initially excited with $2-15 \mathrm{~ms}$ latencies. The distribution of latencies of exclusively and initially excitatory responses of NREM/REM sleep- and REM sleeprelated units is shown in Figure $5 F$.

Four of 14 sleep-related cells responding with $<15$ ms onset latency were operationally defined as monosynaptically activated because they exhibited $<0.5 \mathrm{~ms}$ latency jitter and ability to follow highfrequency stimulation at 70-85 pulses/s (see Fig. $6 B$ ). The rest of the cells were classified as polysynaptically activated.

$\leftarrow$

with EEG desynchronization on arousals from NREM sleep $\left(\boldsymbol{a}_{2}\right) . \boldsymbol{B}$, Response of the same neuron to a single-pulse stimulation of the MnPN. PSTH (bottom panel), raster plot (middle panel), and a raw trace (top panel) of a single stimulation trial marked by arrow are displayed. The neuron responded with a short-latency (3 ms) pure inhibition. C, The discharge of MFM cell across the sleep-waking cycle. $c$, Expanded tracing from $\boldsymbol{C}$ marked by horizontal bar. 1-4, Unit activity tracings corresponding to epochs marked by vertical bars in $C: 1$, NREM sleep; 2 , transition to REM sleep; 3, REM sleep; 4, AW. Note that MFM neurons dramatically increased their firing rates $18-42$ s before REM sleep onset (c) primarily because of an increase in density of high-frequency burst discharges ( $\boldsymbol{c}$, compare 1,2 ). D, Response of the same cell to a single-pulse MnPN stimulation. The neuron responded with a shortlatency ( $4 \mathrm{~ms}$ ) excitation followed by inhibition. The top panel on the left side shows row traces of two single stimulation trials marked by arrows in raster display (middle panel) and on the right-hand side fragment of the PSTH from the bottom panel showing at higher resolution the initial part of the response. 


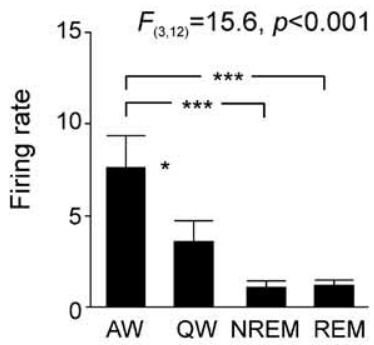

$D$

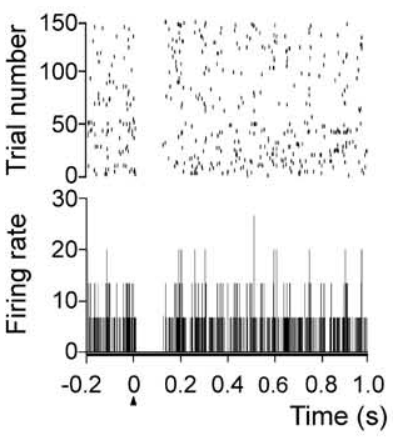

G

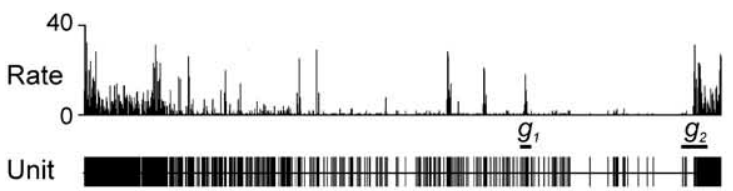

EMG

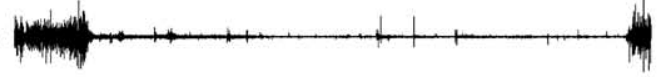

EEG
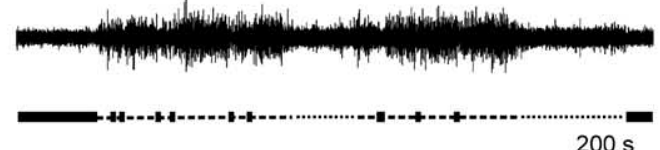

$200 \mathrm{~s}$

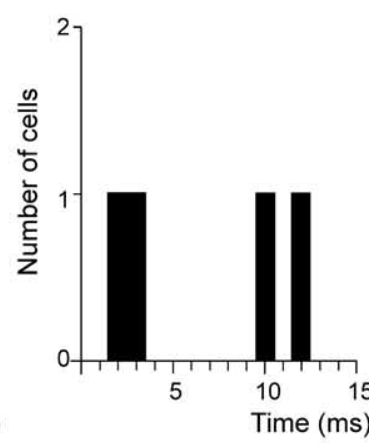

$F$

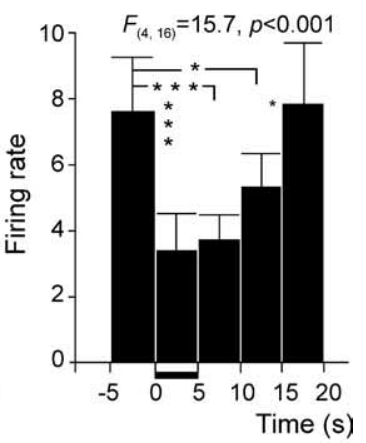

$H$
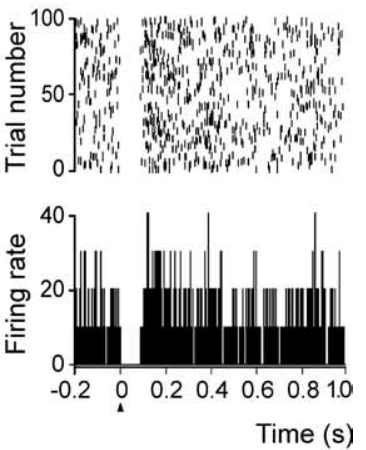

g1

g2
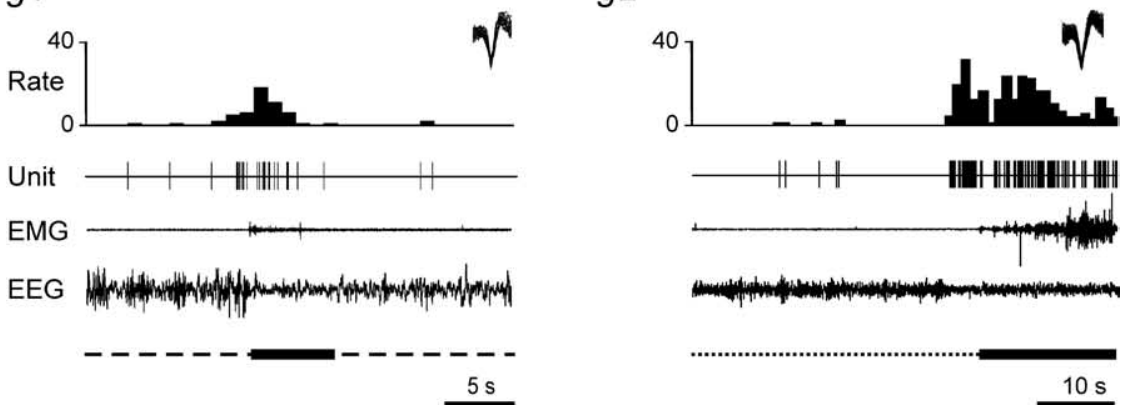

$10 \mathrm{~s}$

Figure 4. Summary of discharge characteristics of AW-related PF/LH neurons and their responses to MnPN electrical stimulation. $A$, Group mean \pm SEM discharge rates of AW-related neurons across sleep-wake states. The mean firing rate in AW was higher compared with QW and both phases of sleep (one-way repeated-measures ANOVA followed by Tukey's HSD test). $\boldsymbol{B}$, Mean discharge rates of individual neurons. $C$, Percentages of different types of responses to single-pulse electrical stimulation of the $\mathrm{MnPN}$. Note that all responders were inhibited by MnPN stimulation. Inh, Inhibitory responses; NR, nonresponsive. $\boldsymbol{D}$, Raster plot and PSTH corresponding to a response that appeared with $10 \mathrm{~ms}$ onset latency. $\boldsymbol{E}$, Histogram of distribution of onset latencies of responses. Note the presence of latencies compatible with a monosynaptic linkage. $\boldsymbol{F}$, Group mean \pm SEM firing rate of AWrelated units calculated for five consecutive 5 s epochs before, during, and after train stimulation of the MnPN. Note that neurons were inhibited during stimulation period (marked with horizontal bar next to $x$-axis) and for 10 s thereafter. $\mathbf{G}$, The discharge of AW-related cell across the sleep-waking cycle. $\boldsymbol{g}_{1}, \boldsymbol{g}_{2}$, Expanded tracings from $\boldsymbol{G}$ marked by horizontal bars. On the top right corner of the expanded tracings superimposed are all action potentials that appeared during corresponding fragments of recordings. Note that neuron increases its firing rate before arousal from NREM sleep $\left(\boldsymbol{g}_{1}\right)$ and awakening from REM sleep $\left(\boldsymbol{g}_{2}\right)$. $\boldsymbol{H}$, PSTH and raster plot showing short-latency ( $2 \mathrm{~ms}$ ) inhibitory response of this cell to single-pulse MnPN stimulation. ${ }^{*} p<0.05$; ${ }^{* *} p<0.001$.
The responses of sleep-related neurons to train stimulation of the MnPN were tested on six NREM/REM sleep- and on five REM sleep-related units. Firing rates of one NREM/REM sleep- and three REM sleep-related neurons were significantly affected by train stimulations $(p<0.001$, one-way repeated-measures ANOVA). All reactions were excitatory and strictly timed to the stimulation period. During stimulation, NREM/REM sleep-related unit increased its discharge by $137 \%$ and REM sleep-related neurons by $30-46 \%$ (mean, $38.9 \pm 4.7 \%$ ) compared with the prestimulation firing rate $(p<0.001$, Tukey's HSD post hoc test). The firing rate was at its maximum at the beginning of stimulation and decreased to the baseline level after 2-3 s. Every cell responsive to train stimulation exhibited exclusively excitatory reactions to single-pulse stimulation, whereas the two cells that did not show significant responses during train stimulation exhibited biphasic excitatory/ inhibitory responses to single pulses.

\section{State-indifferent neurons}

Sleep-wake discharge pattern. Seven $\mathrm{PF} / \mathrm{LH}$ cells $(8 \%)$ with a single-pulse firing mode did not show significant changes in the mean firing rate across sleep-wake states $\left(F_{(3,18)}=1.9 ; p>0.05\right)$. Individual cells exhibited $<25 \%$ between-state differences.

Responses to stimulation. Four stateindifferent neurons responded to a singlepulse stimulation of the MnPN. They showed pure orthodromic excitations, which started 17-26 ms after MnPN stimulation. The mean latency and duration of these responses are shown in Table 1.

Train stimulation of the MnPN had significant effects only on discharge of those cells that showed excitatory response to single-pulse stimulation. The mean firing rates of individual neurons increased during stimulation by $61-105 \%$ (mean, $88.3 \pm 9.5 \%$ ) compared with the baseline. At each of the three poststimulation intervals ( $5 \mathrm{~s}$ each), the firing rate did not differ significantly from the prestimulation value ( $p>0.05$, Tukey's HSD post hoc test).

Comparison of types of PF/LH neuronal responses and their ratios in five rats with different localization of stimulating electrode tips within the MnPN (Fig. 1B) did not reveal differences in responses of either arousal- or sleep-related units. In cases when stimulating electrodes were misplaced ( $\sim 200$ and $400 \mu \mathrm{m}$ laterally or $150 \mu \mathrm{m}$ dorsally/200 $\mu \mathrm{m}$ caudally from MnPN margins), we observed different 
EEG- and PF/LH neuronal responses. Low-frequency stimulation of these sites failed to induce EEG-synchronizing responses, whereas high-frequency stimulation caused EEG desynchronization. Among arousal-related units, we did not find cells exhibiting inhibitory responses with $<15$ ms latency. NREM/REM sleeprelated neurons were either unresponsive (two of three cells) or inhibited by stimulation of extra-MnPN sites.

\section{Responses of PF/LH neurons to chemical stimulation and inhibition of the MnPN}

Activation of $\mathrm{MnPN}$ neuronal populations without influence on passing fibers was achieved by $1 \mathrm{~h}$ microdialytic perfusion of excitatory amino acid L-glutamate or the $\mathrm{GABA}_{\mathrm{A}}$ receptor antagonist, bicuculline, at concentrations of $1 \mathrm{~mm}$ and 50 $\mu \mathrm{M}$, respectively. Experiments were conducted during the dark phase of the light/ dark cycle (ZT13-ZT16), because during application of the drugs in the light phase, sustained waking episodes were absent and, therefore, the effects of MnPN chemical stimulation on discharge of wakeactive PF/LH neurons could not be estimated. Table 2 shows the percentage of time spent in different sleep-wake states $1 \mathrm{~h}$ before and during perfusion of L-glutamate and bicuculline averaged for all experiments conducted during the dark phase.

To assess effects of MnPN deactivation on PF/LH neuronal activity, the MnPN was microdialytically perfused with the $\mathrm{GABA}_{\mathrm{A}}$ receptor agonist, muscimol, during the light phase (ZT3ZT6) of the light/dark cycle. Application of this drug at $50 \mu \mathrm{M}$ concentration for $15 \mathrm{~min}$ resulted in a prolonged AW state, which appeared 1-3 min after the start of muscimol perfusion and lasted for 35-84 min (mean, 61.3 \pm 3.9 ). During the $1 \mathrm{~h}$ period that started from the beginning of drug application compared with $1 \mathrm{~h}$ predrug aCSF perfusion, animals spent $91 \%$ of the time in AW, NREM sleep was dramatically reduced ( $p<0.001$, oneway repeated-measures ANOVA) and REM sleep episodes were almost absent (Table 2).

Perfusion of the MnPN with $50 \mu \mathrm{M}$ muscimol was used to evaluate responses of AW-, AW/REM sleep-related, and stateindifferent units. To examine responses of sleep-related neurons, $20 \mu \mathrm{M}$ muscimol was applied for $1 \mathrm{~h}$ during the lights on phase of the light/dark cycle (ZT3-ZT6). With this lower concentration, sustained periods of NREM and REM sleep were present during drug administration (Table 2).

The effects of chemical stimulation and inhibition of the $\mathrm{MnPN}$ were studied on $36 \mathrm{PF} / \mathrm{LH}$ cells recorded throughout all the stages of the experiment (baseline aCSF perfusion, drug treatment, and postdrug aCSF perfusion). Among these cells, all responsive units recovered their baseline discharge during postdrug aCSF perfusion. In addition, we are reporting responses of 18 neurons, which were recorded during baseline and drug treatments only. Neurons increasing or not changing discharge dur-
$B$

C
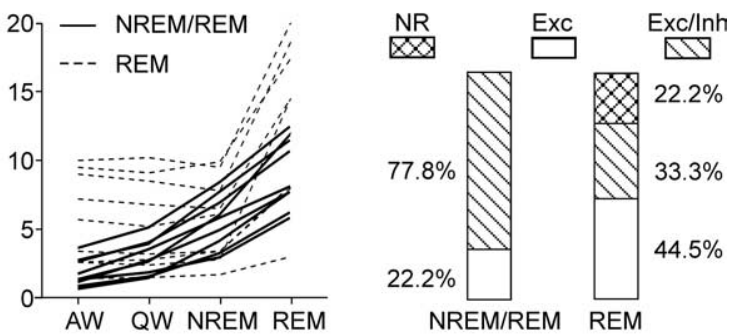

E
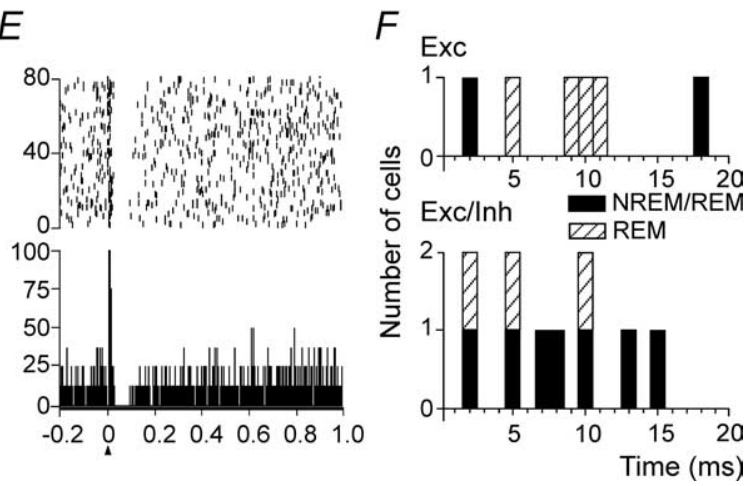

Figure 5. Summary of discharge characteristics of sleep-related PF/LH neurons and their responses to MnPN electrical stimuation. $\boldsymbol{A}$, Group mean \pm SEM discharge rates of NREM/REM sleep-related neurons (black bars) and REM sleep-related neurons

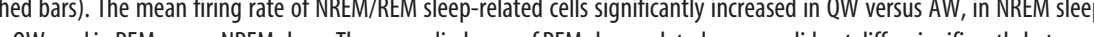
REM sleep-related cells (hatched bars). Note the presence of cells responding with short latencies within both subsets of sleeprelated cells. NR, Nonresponsive; Exc, excitatory; Exc/Inh, excitatory/inhibitory responses. ${ }^{*} p<0.05$; ${ }^{* * *} p<0.001$.

ing the treatments $(n=12)$ were pooled together with the cells recorded throughout the entire experiment. For all neurons decreasing discharge in response to chemical treatments $(n=6)$, the absence of data on recovery of the baseline discharge is emphasized because of uncertainty regarding the cause of changes in the activity of these neurons.

AW/REM sleep-related cells

Effects of chemical stimulation and deactivation of the MnPN were studied on 35 AW/REM sleep-related PF/LH neurons.

The changes in the group mean firing rates of 12 and $8 \mathrm{AW} /$ REM sleep-related units in response to administration of L-glutamate and bicuculline, respectively, are shown in Figure 7, $A$ and $B$. The neuronal responses to these treatments were similar. Two-way repeated-measures ANOVA in both cases revealed significant main effects of within-subjects factors (sleep-wake state and drug treatment) on discharge of AW/REM sleep-related cells and significant interaction between the factors. During L-glutamate and bicuculline administration, the mean firing rate of AW/REM sleep-related cells decreased compared with aCSF perfusion $\left(F_{(1,11)}=45.7, p<0.001\right.$; and $F_{(1,7)}=24.5, p<0.01$, respectively). The effects of both treatments depended on the state of the sleep-waking cycle (L-glutamate: $F_{(3,9)}=5.1, p<$ 0.05 , Wilk's multivariate test; bicuculline: $\left.F_{(3,21)}=4.0, p<0.05\right)$. Discharge suppression during L-glutamate and bicuculline administration was statistically significant only in AW $(p<0.001$ 
$A$

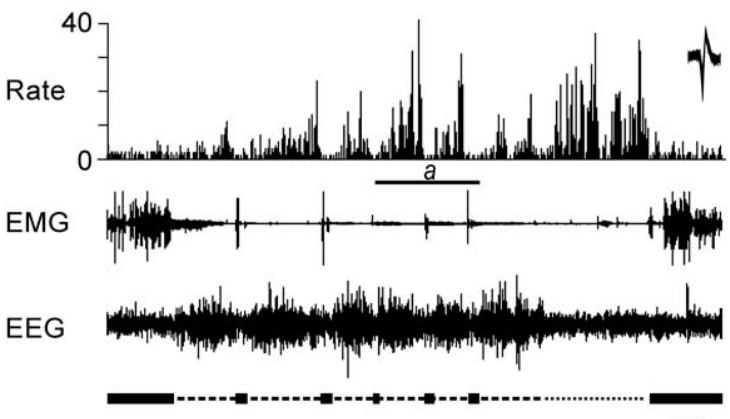

$\underline{60 \mathrm{~s}}$

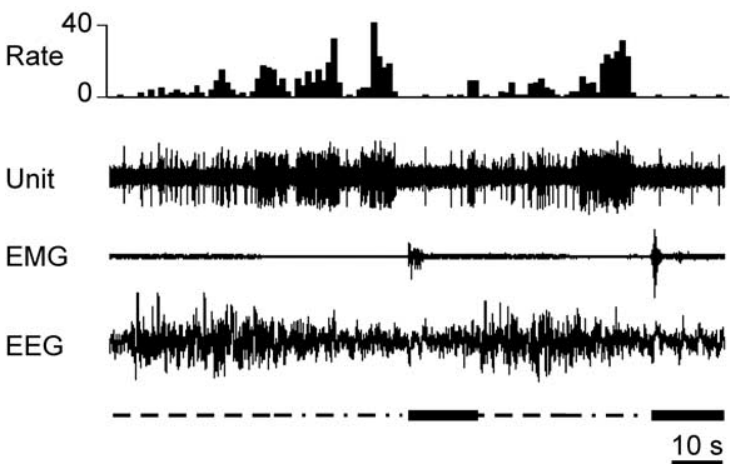

$B$
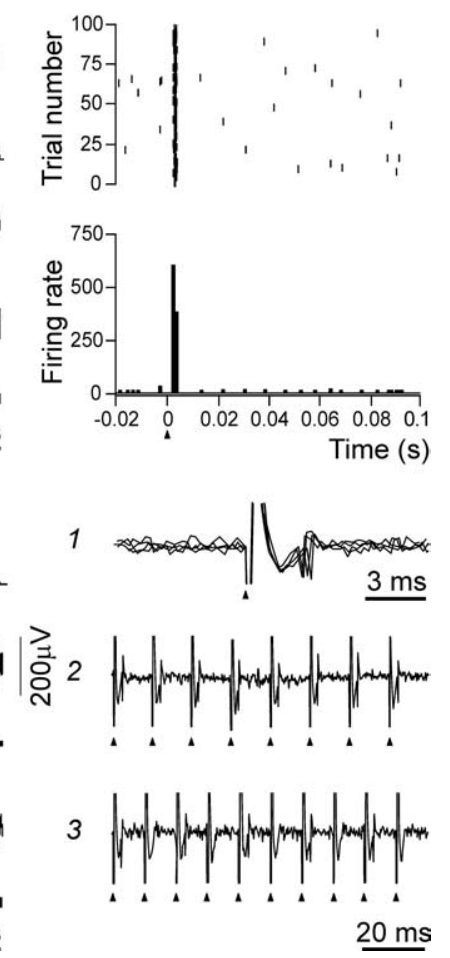

Figure 6. Representative example of the response of an NREM/REM sleep-related PF/LH neuron to MnPN electrical stimulation. $\boldsymbol{A}$, The discharge of the cell across the sleep-waking cycle. $\boldsymbol{a}$, Expanded tracings from $\boldsymbol{A}$ marked by horizontal bar. Note that NREM/REM sleep-related neurons ceased to discharge or dramatically reduced their firing rates a few seconds before arousal. $\boldsymbol{B}$, Response of this cell to MnPN electrical stimulation. Raster plot, PSTH, superposition of raw traces of five consecutive stimulation trials (1), and neuronal responses to 80 (2) and 100 pulses/s (3) repetitive stimuli are displayed. Note short latency (2 ms), low jitter of response (1), and ability of the cell to follow repetitive stimuli at $80 \mathrm{pulses} / \mathrm{s}$ (2). At $100 \mathrm{pulses} / \mathrm{s}$, the neuron responds only to every other stimuli (3). These findings suggest monosynaptic activation.

and $p<0.01$, respectively; Tukey's HSD test). Individually, in AW in response to L-glutamate and bicuculline treatments, 92 and $85 \%$ of neurons, respectively, exhibited changes in their activity meeting the response criterion $(>25 \%$ change in the firing rate). No cells were activated. During L-glutamate and bicuculline perfusion, responsive cells reduced their discharge to $34.7 \pm$ $4.0 \%$ (range, $11-59 \%$ ) and to $58.5 \pm 4.3 \%$ (range, $44-73 \%$ ) of baseline firing, respectively. The effect of L-glutamate on discharge of an individual cell across sleep-wake states is shown in Figure $8 \mathrm{~A}$. All cells recorded during baseline and drug treatment only $(n=3)$ reduced their discharge in response to L-glutamate $(n=2)$ and bicuculline $(n=1)$ treatments to $29-45 \%$ of baseline firing and were not included into statistical analysis.

The effects of MnPN perfusion with muscimol were studied on 12 AW/REM sleep-related cells. During the muscimolinduced AW state, the mean firing rate of these neurons as a group increased $\left(F_{(1,11)}=23.9, p<0.001\right.$, one-way repeatedmeasures ANOVA) (Fig. 7C). Individually, 75\% of cells increased their discharge on average to $220.8 \pm 48.5 \%$ (range, $134-600 \%$ ) of baseline firing; the rest of the cells were unresponsive. The effect of muscimol perfusion on discharge of AW/REM sleeprelated neuron is shown in Figure $8 B$.

\section{AW-related cells}

Responses of seven AW-related PF/LH neurons to microdialytic application of L-glutamate $(n=3)$, bicuculline $(n=2)$, and muscimol $(n=2)$ into the MnPN were studied.

Figure $8 C$ shows the effect of $\mathrm{MnPN}$ perfusion with
L-glutamate on discharge of an AWrelated PF/LH unit. During drug administration, compared with predrug aCSF perfusion, the cell exhibited a $98 \%$ reduction in its firing rate and became virtually silent in AW, whereas during QW and NREM sleep the changes of discharge rate did not exceed $25 \%$. REM sleep did not occur during drug perfusion. L-Glutamate treatment changed the firing rate of one of two cells, which were lost during postdrug aCSF perfusion. This neuron decreased discharge only in AW to $57 \%$ of baseline firing.

In response to bicuculline administration, one unit almost ceased to discharge during the whole period of drug perfusion, whereas the other cell showed $44 \%$ decrease in its firing rate exclusively during AW.

During MnPN perfusion with muscimol, one neuron increased discharge by $43 \%$, and the other was unresponsive.

\section{Sleep-related cells}

A total of 11 sleep-related $\mathrm{PF} / \mathrm{LH}$ neurons were tested for responses to MnPN perfusion with L-glutamate $(n=2)$, bicuculline $(n=3)$, and muscimol $(n=6)$.

Microdialytic application of Lglutamate resulted in a dramatic increase in the firing rate of a NREM/REM sleeprelated neuron to $250,500,260$, and $190 \%$ of baseline firing in AW, QW, NREM, and REM sleep, respectively (Fig. 9A). An REM sleep-related cell increased discharge by 28 and $42 \%$ in NREM and REM sleep, respectively.

During bicuculline perfusion, two NREM/REM sleep-related units increased their firing rates by 44 and 54\% in AW and by 44 and $120 \%$ in QW. During NREM sleep, the changes in the activity of one cell did not meet the response criterion; the other neuron increased firing by 63\%. During REM sleep, spike activity of these cells increased by 25 and 29\%. An REM sleep-related neuron was unresponsive to bicuculline treatment.

In response to muscimol perfusion, the discharge of one of two NREM/REM sleep-related cells decreased by 43 and $25 \%$ during NREM and REM sleep, respectively, and by $<25 \%$ during waking (Fig. 9B). A unit that was not recorded during postdrug aCSF perfusion also exhibited a reduction of firing to 27,34 , and $45 \%$ of baseline values during QW, NREM, and REM sleep, respectively. Two of four REM sleep-related cells (one with verified recovery of the baseline discharge, the other not recorded during postdrug aCSF perfusion) exhibited 37 and 28\% decreases in firing rates exclusively during REM sleep. The remaining REM sleep-related neurons did not exhibit criterion responses to muscimol.

\section{State-indifferent neurons}

In total, responses of eight state-indifferent PF/LH units to chemical treatments of the MnPN were analyzed.

The firing rate of five $\mathrm{PF} / \mathrm{LH}$ state-indifferent neurons was not affected by MnPN perfusion with L-glutamate $(n=2)$ and muscimol $(n=3)$ by $>10 \%$. One cell increased discharge by $28 \%$ in response to microdialytic application of L-glutamate. MnPN per- 
Table 2. The percentage of time spent in different stages of the sleep-waking cycle during consecutive $1 \mathrm{~h}$ periods corresponding to predrug aCSF perfusion (baseline) and chemical treatments of the MnPN

\begin{tabular}{|c|c|c|c|c|c|c|c|c|}
\hline \multirow[b]{2}{*}{ State } & \multicolumn{2}{|c|}{$\begin{array}{l}\text { L-Glutamate }(1 \mathrm{~mm}) \\
(n=21)\end{array}$} & \multicolumn{2}{|c|}{$\begin{array}{l}\text { Bicuculline }(50 \mu \mathrm{m}) \\
(n=18)\end{array}$} & \multicolumn{2}{|c|}{$\begin{array}{l}\text { Muscimol }(50 \mu \mathrm{m}) \\
(n=15)\end{array}$} & \multicolumn{2}{|c|}{$\begin{array}{l}\text { Muscimol }(20 \mu \mathrm{m}) \\
(n=5)\end{array}$} \\
\hline & Baseline & Treatment & Baseline & Treatment & Baseline & Treatment & Baseline & Treatment \\
\hline Active waking & $55.5 \pm 1.6$ & $47.1 \pm 2.0^{*}$ & $50.1 \pm 3.1$ & $40.4 \pm 2.6^{* *}$ & $17.2 \pm 1.3$ & $91.2 \pm 3.7^{* * *}$ & $19.0 \pm 1.4$ & $25.2 \pm 2.9^{*}$ \\
\hline Quiet waking & $14.0 \pm 0.6$ & $16.7 \pm 0.8^{* *}$ & $14.9 \pm 1.0$ & $17.9 \pm 1.0^{*}$ & $11.2 \pm 0.8$ & $5.1 \pm 1.9^{* * *}$ & $13.4 \pm 1.9$ & $16.8 \pm 1.9$ \\
\hline NREM sleep & $25.5 \pm 1.6$ & $30.2 \pm 1.8^{* *}$ & $30.9 \pm 3.0$ & $36.0 \pm 2.5$ & $60.3 \pm 1.6$ & $2.3 \pm 1.6^{* * *}$ & $56.6 \pm 3.5$ & $46.4 \pm 5.0^{*}$ \\
\hline REM sleep & $5.0 \pm 0.5$ & $6.0 \pm 0.4$ & $4.1 \pm 0.6$ & $5.7 \pm 0.6$ & $11.3 \pm 0.7$ & $0.7 \pm 0.5^{* * *}$ & $11.0 \pm 1.0$ & $11.6 \pm 1.4$ \\
\hline
\end{tabular}

${ }^{*} p<0.05,{ }^{* *} p<0.01$, and ${ }^{* * *} p<0.001$, one-way repeated-measures ANOVA.

fusion with bicuculline caused a 35-75\% increase in the firing rate of two tested units.

In animals with slightly different microdialysis probe localization within the MnPN (Fig. 1E), the effects of chemical treatments on both sleep-wake states and $\mathrm{PF} / \mathrm{LH}$ neuronal discharge were uniform. Microdialysis probes missed the target in two cases. In one case with a $250 \mu \mathrm{m}$ lateral localization, the behavioral and neuronal responses to the chemical treatment were similar to those found in cases with $\mathrm{MnPN}$ localization. However, in a probe placed $400 \mu \mathrm{m}$ lateral and $300 \mu \mathrm{m}$ dorsal to the MnPN, chemical treatments produced opposite behavioral and $\mathrm{PF} / \mathrm{LH}$ neuronal responses compared with MnPN treatments.

\section{Discussion}

This study provides new evidence for a functional role of afferent inputs from the $\mathrm{MnPN}$ to PF/LH neurons with different sleep-wake discharge patterns. Arousal- and sleep-related PF/LH cells exhibited reciprocal responses to electrical stimulation or local chemical manipulation of the MnPN. Responsive arousal-related neurons were predominantly inhibited, whereas sleep-related cells were excited by $\mathrm{MnPN}$ electrical or chemical stimulation. Furthermore, MnPN chemical deactivation suppressed sleep and resulted in increased activity of most arousal-related neurons and reduced discharge of most sleep-related cells. We hypothesize that MnPN sleep-active neurons along with the other elements of the preoptic area/basal forebrain sleep-promoting system participate in the inhibitory control PF/LH arousal-promoting mechanisms via inhibition of arousal-related and activation of sleep-related PF/LH neurons.

\section{Sleep-wake discharge profiles of $\mathrm{PF} / \mathrm{LH}$ neurons}

As in previous studies of $\mathrm{PF} / \mathrm{LH}$ region (Alam et al., 2002; Koyama et al., 2003), we found AW-related, AW/REM sleeprelated, REM sleep-related, and state-indifferent cells. In addition, we identified a new group of NREM/REM sleep-related neurons. These cells increased their discharge during QW and NREM sleep and reached a peak of activity in REM sleep. Neurons with similar discharge profile were found within the preoptic area/basal forebrain (Szymusiak et al., 1998; Suntsova et al., 2002; Lee et al., 2004) and were hypothesized to be involved in sleep-promoting mechanisms via inhibition of wake-promoting neuronal groups. The NREM/REM sleep-related discharge profile could be characteristic of GABAergic PF/LH neurons (Rosin et al., 2003) exhibiting increased c-Fos expression during sleep
(Kumar et al., 2005) or cells containing inhibitory peptide $\mathrm{MCH}$ (Gao and van den Pol, 2001) or colocalizing MCH and GABA (Elias et al., 2001; Harthoorn et al., 2005). MCH cells are believed to be REM sleep-related based on elevated c-Fos immunoreactivity in $\mathrm{MCH}$ neurons during recovery sleep after REM sleep deprivation and greater increase of REM versus NREM sleep in response to intracerebroventricular $\mathrm{MCH}$ administration (Verret et al., 2003). However, the latter studies do not exclude a possibility that MCH neurons are NREM/REM sleep related.

\section{Effects of the MnPN on PF/LH neurons}

In the present study, two complementary methods were used to manipulate $\mathrm{MnPN}$ efferent flow: electrical stimulation and chemical activation/inhibition. The issues related to advantages/ limitations of each methodology, selection of stimulation parameters and concentrations of drugs, effective spread of current and drugs were addressed in Materials and Methods. The effects of $\mathrm{MnPN}$ electrical stimulation on discharge of $\mathrm{PF} / \mathrm{LH}$ neurons were in accordance with effects of chemical stimulation and opposite to effects of chemical inhibition. The responses to chemical treatments are consistent with involvement of MnPN efferents in mediating neuronal responses to electrical stimulation, although a possible role of activation of passing fibers and/or axonal terminals could not be completely excluded. The geometry and placement of bipolar electrodes were designed to focus stimulation in the MnPN. However, stimulation could also partially activate neural elements within adjacent structures. A relatively small effective spread of current in our study is supported by the fact that $150-200 \mu \mathrm{m}$ shifts in stimulating electrode position beyond MnPN margins resulted in significant changes in both 


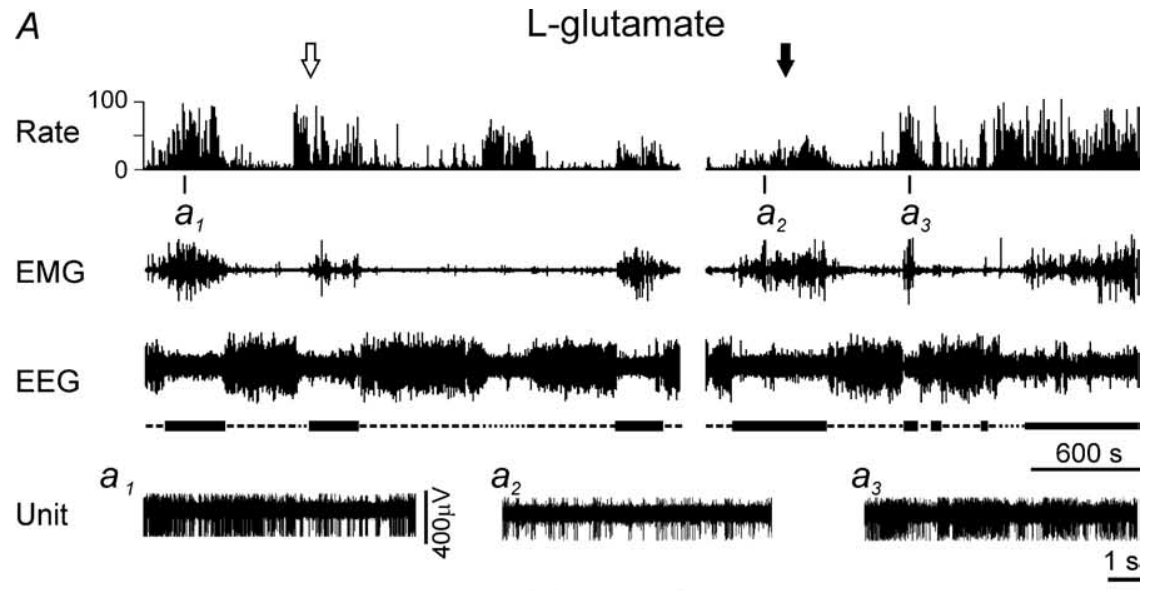

$B$

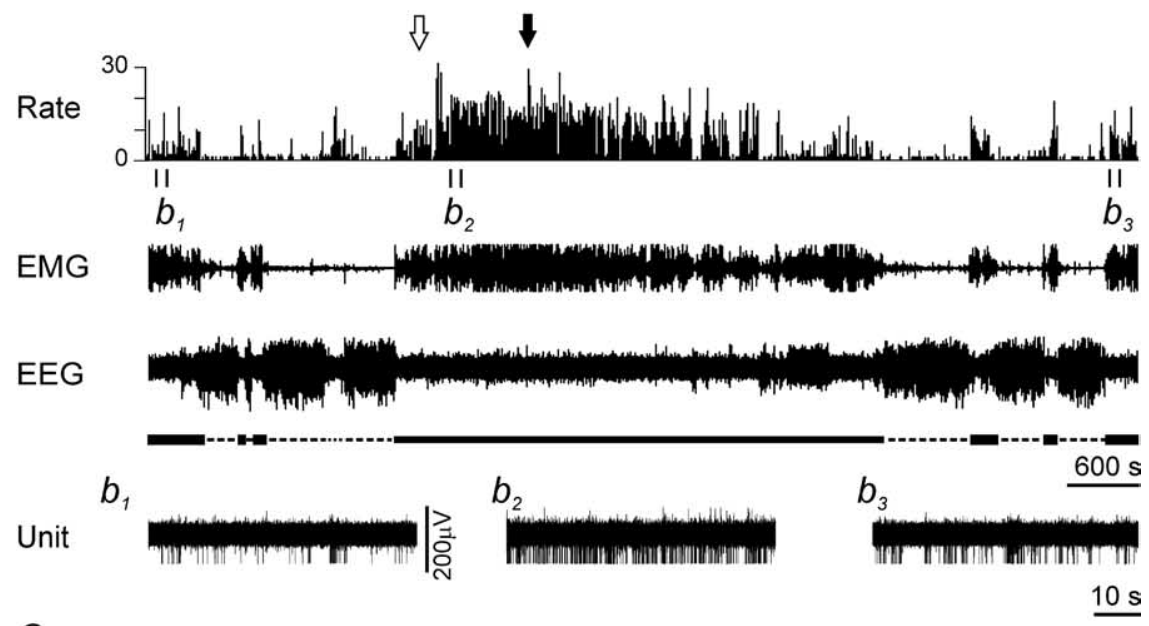

C

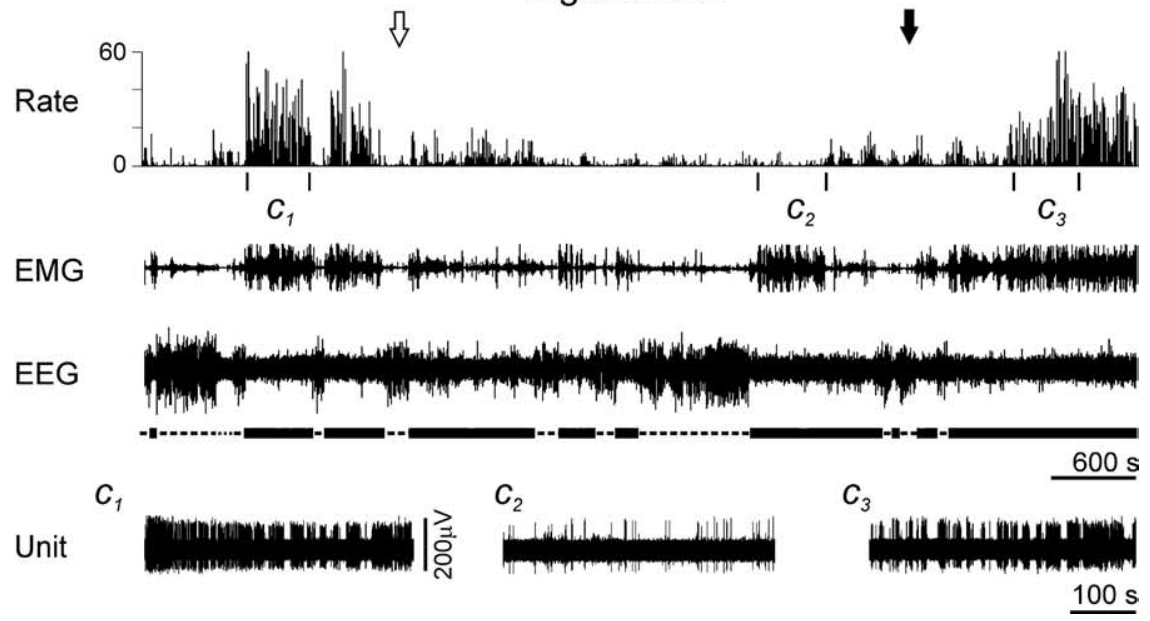

Figure 8. Representative examples of the effects of MnPN chemical activation and inhibition on discharge of arousal-related $\mathrm{PF} / \mathrm{LH}$ neurons. $\boldsymbol{A}, \boldsymbol{B}$, Effects of microdialytic perfusion of the MnPN with $1 \mathrm{~mm} \mathrm{~L}$-glutamate and $50 \mu \mathrm{m}$ muscimol, respectively, on activity of AW/REM sleep-related neurons. C, Effect of $1 \mathrm{~mm}$ L-glutamate on the activity of an AW-related cell. The arrows indicate the beginning (white arrow) and the end (black arrow) of drug perfusion. Expanded tracings from the sections marked by vertical bars show neuronal discharge in AW before $\left(\boldsymbol{a}_{1}, \boldsymbol{b}_{1}, \boldsymbol{c}_{7}\right)$, during $\left(\boldsymbol{a}_{2}, \boldsymbol{b}_{2}, \boldsymbol{c}_{2}\right)$, and after $\left(\boldsymbol{a}_{3}, \boldsymbol{b}_{3}, \boldsymbol{c}_{3}\right)$ microdialysis of L-glutamate or muscimol. Note a decrease of neuronal discharge in AW during L-glutamate perfusion and an increase during muscimol perfusion.

EEG and PF/LH neuronal responses. Chemical treatments of the MnPN might cause buildup of an effective concentration of drugs in a number of surrounding structures. Activation/inhibition of the medial septum and the diagonal band of Broca are unlikely to account for observed responses because these struc- tures do not project to the $\mathrm{PF} / \mathrm{LH}$ in rats, whereas medial and lateral parts of the preoptic area and organum vasculosum of the lamina terminalis are important sources of afferents to the PF/LH (Yoshida et al., 2006). Based on our estimates of effective spread of drugs, it is unlikely, but we cannot exclude the possibility that chemical treatments of the MnPN influenced activity of VLPO sleep-active neurons, another possible source of inhibitory control of PF/LH arousal mechanisms. Therefore, although most of our evidence shows that PF/LH neuronal responses mainly resulted from activation/inhibition of MnPN neurons, the possibility of involvement of cells in adjacent preoptic area subregions should be taken into account.

It is established that MnPN neurons send projections to the PF/LH (Gong et al., 2004; Sakurai et al., 2005; Uschakov et al., 2005) and the MnPN input to the $\mathrm{PF} / \mathrm{LH}$ is one of the heaviest among the regions implicated in sleep-waking cycle control (Yoshida et al., 2006). Therefore, it is not surprising that activation/inhibition of the MnPN altered activity of the majority of $\mathrm{PF} / \mathrm{LH}$ neurons and a significant proportion of cells exhibited short-latency responses to $\mathrm{MnPN}$ electrical stimulation.

MnPN deactivation by $50 \mu \mathrm{M}$ muscimol strongly suppressed sleep and increased the activity of AW- and AW/REM sleep-related PF/LH neurons, in accordance with our finding that microinjection of muscimol into the MnPN induces Fos in hypocretin-immunoreactive and nonhypocretin/non-MCH PF/LH cells (Alam et al., 2005b).

During MnPN chemical activation, responsive arousal-related neurons reduced their discharge primarily in AW. The majority of AW- and AW/REM sleep-related neurons exhibited exclusively or initially inhibitory responses to $\mathrm{MnPN}$ electrical stimulation. Extracellular recordings do not allow discrimination between the roles of active inhibition and disfacilitation in suppression of neuronal discharge. However, short-latency inhibitory responses are likely to have resulted from activation of GABAergic sleep-active $\mathrm{MnPN}$ neurons, which were identified as one of the sources of projections to the PF/LH (Gong et al., 2004; Uschakov et al., 2005). Nearly $30 \%$ of inhibited cells responded to MnPN stimulation with 1-3 ms latencies compatible with monosynaptic linkage. Given that a significant number of MnPN-PF/LH projection fibers are unmyelinated (A. Uschakov, personal communications) and MnPN efferents to other hypothalamic structures have low conduction velocity (Stocker and Toney, 2005), it is possible that some cells 
responding with latencies up to $15 \mathrm{~ms}$ were inhibited monosynaptically.

One of the possible indirect mechanisms underlying inhibitory control of arousal-related $\mathrm{PF} / \mathrm{LH}$ neurons by the $\mathrm{MnPN}$ is activation of inhibitory $\mathrm{PF} / \mathrm{LH}$ cells, which should exhibit sleep-related discharge profile. As noted above, sleeprelated $\mathrm{PF} / \mathrm{LH}$ neurons are putatively GABAergic and/or contain MCH. Excitation of $\mathrm{MCH}$ cells rather than disinhibition (Goutagny et al., 2005; Modirrousta et al., 2005) seems to play a critical role in their sleep-related activation, because in vitro $\mathrm{MCH}$ neurons are virtually silent (Eggermann et al., 2003; van den Pol et al., 2004; Bayer et al., 2005). Our data suggest that the MnPN contains cells that exert excitatory control over sleep-related PF/LH neurons. Responsive NREM/REM sleep- and REM sleep-related PF/LH units exhibited exclusively or initially excitatory responses to $\mathrm{MnPN}$ electrical stimulation, and a number of responses met the criteria for monosynapticity. During chemical stimulation and inhibition of the MnPN, responsive sleep-related units increased and reduced their discharge, respectively. Most likely, excitatory inputs to $\mathrm{PF} / \mathrm{LH}$ sleep-related neurons originate in a subset of sleep-related MnPN cells. A substantial number $(30-50 \%)$ of MnPN neurons exhibiting sleep-related c-Fos immunoreactivity are not GABAergic (Gong et al., 2004; Gvilia et al., 2005). We hypothesize that $\mathrm{MnPN}$ sleep-promoting neuronal population is either cytochemically heterogeneous (includes both GABAergic neurons and excitatory cells with unknown neurotransmitter phenotype) or contains neurons that colocalize excitatory and inhibitory neurotransmitters as occurs in dual phenotype GABA/glutamate cells in adjacent anteroventral periventricular nucleus (Ottem et al., 2004).

Notably, the MnPN also projects to VLPO sleep-active neurons (Chou et al., 2002). If these projections originate in sleep-related cells, they are expected to be excitatory. Activation of GABA/galaninergic VLPO neurons projecting to the PF/LH (Sakurai et al., 2005; Uschakov et al., 2006; Yoshida et al., 2006) is likely to be a complementary mechanism of inhibitory control of PF/LH arousal network.

$\mathrm{MnPN}$ neurons are functionally heterogeneous. In addition to predominant sleep-active cells, the MnPN contains waking/REM sleep-related and state-indifferent neurons (Suntsova et al., 2002). Sleep-active MnPN cells do not participate in mechanisms of hydromineral homeostasis and cardiovascular regulation (Gvilia et al., 2005). A role of MnPN-PF/LH interactions in the latter mechanisms is well documented (Kelly

A

EMG

EEG
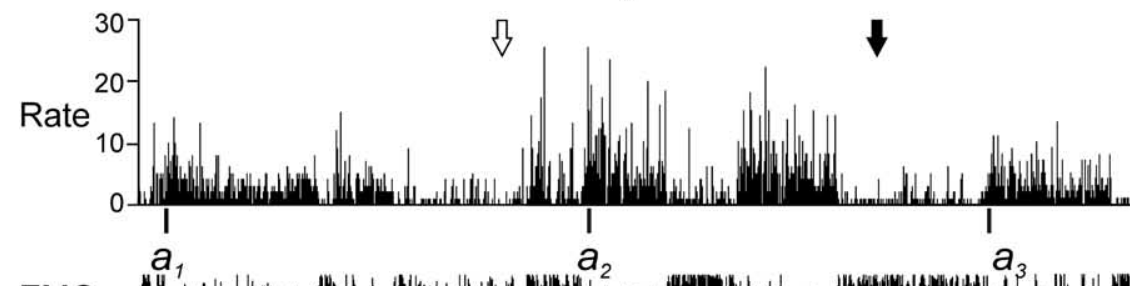

$a_{3}$
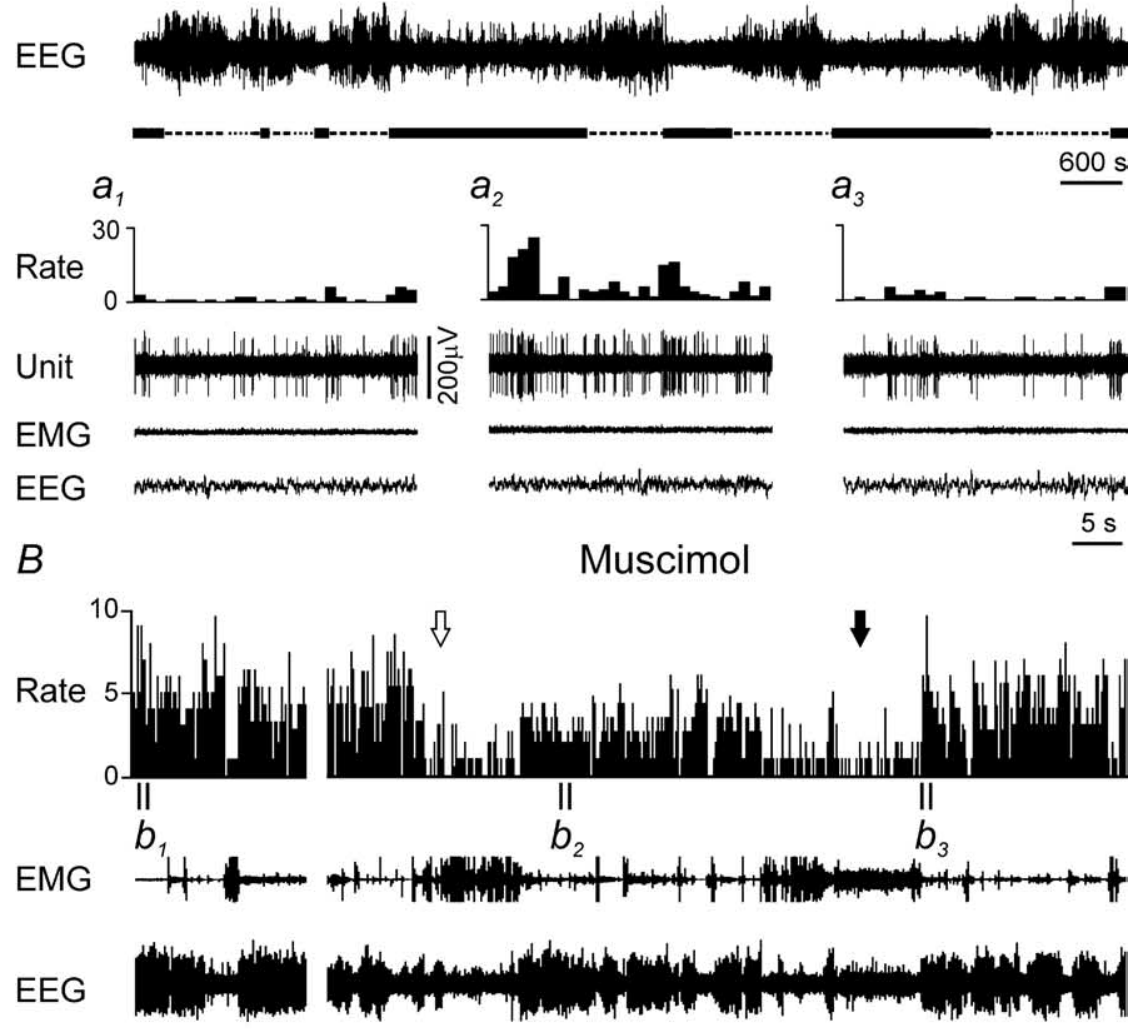

$600 \mathrm{~s}$

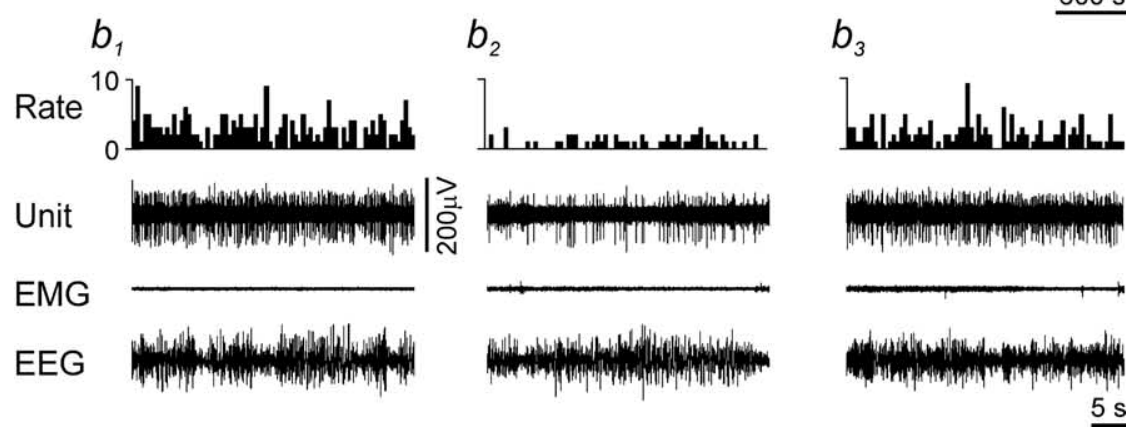

Figure 9. Examples of effects of MnPN chemical activation and inhibition on discharge of PF/LH sleep-related neurons. $\boldsymbol{A}, \boldsymbol{B}$, Effects of microdialytic perfusion of the MnPN with $1 \mathrm{~mm}$ L-glutamate and $20 \mu \mathrm{m}$ muscimol, respectively. The arrows indicate the beginning (white arrow) and the end (black arrow) of drug perfusion. Expanded tracings from the sections marked by vertical bars show neuronal discharge in QW episode preceding NREM sleep before $\left(\boldsymbol{a}_{\mathbf{7}}\right)$, during $\left(\boldsymbol{a}_{\mathbf{2}}\right)$, and after $\left(\boldsymbol{a}_{\mathbf{3}}\right)$ microdialysis of L-glutamate and in NREM sleep before $\left(\boldsymbol{b}_{\boldsymbol{1}}\right)$, during $\left(\boldsymbol{b}_{\mathbf{2}}\right)$, and after $\left(\boldsymbol{b}_{\mathbf{3}}\right)$ microdialysis of muscimol. Note an increase of neuronal discharge during L-glutamate perfusion and a decrease during muscimol perfusion.

and Watts, 1996; Saad et al., 2004). MnPN neurons involved in arousal control and/or serving hydromineral homeostatic and cardiovascular functions may be possible sources of initially excitatory responses or postinhibitory excitations found in subsets of AW/REM sleep-related neurons, postexcitatory inhibitions of 
sleep-related cells, and pure orthodromic excitations of stateindifferent neurons.

Several lines of evidence suggest that MnPN sleep-active neurons are involved in sleep-promoting mechanisms. These cells increase discharge before sleep onset and during both NREM and REM sleep (Suntsova et al., 2002). Activation of MnPN sleepactive neurons reflects a homeostatic sleep drive (Suntsova et al., 2002; Gvilia et al., 2006). Here, we show that MnPN inactivation results in sustained wakefulness. Many MnPN sleep-active neurons are GABAergic and project to different neuronal groups involved in arousal control, including the PF/LH (Uschakov et al., 2006), one of the key components of the wake-promoting system. Our data indicate that majority of $\mathrm{PF} / \mathrm{LH}$ wake-active neurons receive inhibitory inputs from the MnPN. Most likely, the source of these inputs is the GABAergic sleep-active MnPN neuronal population. Inhibition of $\mathrm{PF} / \mathrm{LH}$ wake-promoting cells during QW and sleep may be one of the mechanisms the MnPN sleep-active neurons participate in inhibitory control of $\mathrm{PF} / \mathrm{LH}$ arousal-promoting system. Our data also suggest a complementary mechanism, namely, excitation of PF/LH sleep-related cells, which may, in turn, inhibit wake-related neurons located within the PF/LH and/or within the other wake-promoting regions. The existence of both inhibitory and excitatory outputs from the $\mathrm{MnPN}$ sleep-promoting neurons may be of critical importance for their role in sleep initiation and maintenance via inhibition of arousal-related and excitation of local inhibitory sleep-related cells within the PF/LH and other arousal-related sites of the brain innervated by the MnPN sleep-active neurons.

\section{References}

Alam MN, Gong H, Alam T, Jaganath R, McGinty D, Szymusiak R (2002) Sleep-waking discharge patterns of neurons recorded in the rat perifornical lateral hypothalamic area. J Physiol (Lond) 538:619-631.

Alam MN, Kumar S, Bashir T, Suntsova N, Methippara MM, Szymusiak R, McGinty D (2005a) GABA-mediated control of hypocretin- but not melanin-concentrating hormone-immunoreactive neurones during sleep in rats. J Physiol (Lond) 563:569-582.

Alam MN, Kumar S, Bashir T, Suntsova N, Rai S, Angara C, Szymusiak R, McGinty D (2005b) Median preoptic nucleus modulates C-FOS expression in hypocretin and other perifornical-lateral hypothalamic area neurons in anesthetized rats. Sleep 28:A33.

Bagshaw EV, Evans MH (1976) Measurement of current spread from microelectrodes when stimulating within the nervous system. Exp Brain Res 25:391-400.

Barone FC, Cheng JT, Wayner MJ (1994) Reticular thalamic inhibitory input to lateral hypothalamic neurons - a functional and histochemical determination. Brain Res Bull 33:575-582.

Bayer L, Mairet-Coello G, Risold PY, Griffond B (2002) Orexin/hypocretin neurons: chemical phenotype and possible interactions with melaninconcentrating hormone neurons. Regul Pept 104:33-39.

Bayer L, Eggermann E, Serafin M, Grivel J, Machard D, Muhlethaler M, Jones BE (2005) Opposite effects of noradrenaline and acetylcholine upon hypocretin/orexin versus melanin concentrating hormone neurons in rat hypothalamic slices. Neuroscience 130:807-811.

Chou TC, Bjorkum AA, Gaus SE, Lu J, Scammell TE, Saper CB (2002) Afferents to the ventrolateral preoptic nucleus. J Neurosci 22:977-990.

de Lecea L, Sutcliffe JG (2005) The hypocretins and sleep. FEBS J 272:5675-5688.

Eggermann E, Bayer L, Serafin M, Saint-Mleux B, Bernheim L, Machard D, Jones BE, Muhlethaler M (2003) The wake-promoting hypocretinorexin neurons are in an intrinsic state of membrane depolarization. J Neurosci 23:1557-1562.

Elias CF, Lee CE, Kelly JF, Ahima RS, Kuhar M, Saper CB, Elmquist JK (2001) Characterization of CART neurons in the rat and human hypothalamus. J Comp Neurol 432:1-19.

Estabrooke IV, McCarthy MT, Ko E, Chou TC, Chemelli RM, Yanagisawa M, Saper CB, Scammell TE (2001) Fos expression in orexin neurons varies with behavioral state. J Neurosci 21:1656-1662.
Fan YP, Horn EM, Waldrop TG (2000) Biophysical characterization of rat caudal hypothalamic neurons: Calcium channel contribution to excitability. J Neurophysiol 84:2896-2903.

Follett KA, Mann MD (1986) Effective stimulation distance for current from macroelectrodes. Exp Neurol 92:75-91.

Gao XB, van den Pol AN (2001) Melanin concentrating hormone depresses synaptic activity of glutamate and GABA neurons from rat lateral hypothalamus. J Physiol (Lond) 533:237-252.

Georges F, Aston-Jones G (2001) Potent regulation of midbrain dopamine neurons by the bed nucleus of the stria terminalis. J Neurosci 21:RC160(1-6).

Gerashchenko D, Shiromani PJ (2004) Different neuronal phenotypes in the lateral hypothalamus and their role in sleep and wakefulness. Mol Neurobiol 29:41-59.

Gong H, McGinty D, Guzman-Marin R, Chew KT, Stewart D, Szymusiak R (2004) Activation of c-fos in GABAergic neurones in the preoptic area during sleep and in response to sleep deprivation. J Physiol (Lond) 556:935-946.

Goutagny R, Luppi PH, Salvert D, Gervasoni D, Fort P (2005) GABAergic control of hypothalamic melanin-concentrating hormone-containing neurons across the sleep-waking cycle. NeuroReport 16:1069-1073.

Gvilia I, Angara C, McGinty D, Szymusiak R (2005) Different neuronal populations of the rat median preoptic nucleus express c-fos during sleep and in response to hypertonic saline or angiotensin-II. J Physiol (Lond) 569:587-599.

Gvilia I, Xu F, McGinty D, Szymusiak R (2006) Homeostatic regulation of sleep: a role for preoptic area. J Neurosci 26:9426-9433.

Hanamori T (2003) Chemical stimulation of the thalamic reticular nucleus inhibits the neuronal activity of the posterior insular cortex in rats. Chem Senses 28:717-728.

Harthoorn LF, Sane A, Nethe M, Van Heerikhuize JJ (2005) Multitranscriptional profiling of melanin-concentrating hormone and orexincontaining neurons. Cell Mol Neurobiol 25:1209-1223.

Jones BE, Muhlethaler M (2005) Modulation of cortical activity and sleepwake state by hypocretin/orexin. In: The hypocretins: integrators of physiological functions (de Lecea L, Sutcliffe JG, eds), pp 289-301. New York: Springer.

Karreman M, Moghaddam B (1996) The prefrontal cortex regulates the basal release of dopamine in the limbic striatum: an effect mediated by ventral tegmental area. J Neurochem 66:589-598.

Kelly AB, Watts AG (1996) Mediation of dehydration-induced peptidergic gene expression in the rat lateral hypothalamic area by forebrain afferent projections. J Comp Neurol 370:231-246.

Koyama Y, Takahashi K, Kodama T, Kayama Y (2003) State-dependent activity of neurons in the perifornical hypothalamic area during sleep and waking. Neuroscience 119:1209-1219.

Kumar S, Szymusiak R, Rai S, Methippara M, Suntsova N, McGinty D, Alam NM (2005) Sleep-wake-dependent Fos expression in glutamatergic and GABAergic neurons in the perifornical lateral hypothalamic area. Soc Neurosci Abstr 31:63.17.

Lee MG, Manns ID, Alonso A, Jones BE (2004) Sleep-wake related discharge properties of basal forebrain neurons recorded with micropipettes in head-fixed rats. J Neurophysiol 92:1182-1198.

Lee MG, Hassani OK, Jones BE (2005) Discharge of identified orexin/hypocretin neurons across the sleep-waking cycle. J Neurosci 25:6716-6720.

Lin JS (2000) Brain structures and mechanisms involved in the control of cortical activation and wakefulness, with emphasis on the posterior hypothalamus and histaminergic neurons. Sleep Med Rev 4:471-503.

Lin JS, Sakai K, Vannimercier G, Jouvet M (1989) A critical role of the posterior hypothalamus in the mechanisms of wakefulness determined by microinjection of muscimol in freely moving cats. Brain Res 479:225-240.

Materi LM, Semba K (2001) Inhibition of synaptically evoked cortical acetylcholine release by intracortical glutamate: involvement of GABAergic neurons. Eur J Neurosci 14:38-46.

Methippara MM, Alam N, Szymusiak R, McGinty D (2003) Preoptic area warming inhibits wake-active neurons in the perifornical lateral hypothalamus. Brain Res 960:165-173.

Mileykovskiy BY, Kiyashchenko LI, Siegel JM (2005) Behavioral correlates of activity in identified hypocretin/orexin neurons. Neuron 46:787-798.

Modirrousta M, Mainville L, Jones BE (2005) Orexin and MCH neurons express c-Fos differently after sleep deprivation vs. recovery and bear different adrenergic receptors. Eur J Neurosci 21:2807-2816. 
Ottem EN, Godwin JG, Krishnan S, Petersen SL (2004) Dual-phenotype GABA/glutamate neurons in adult preoptic area: sexual dimorphism and function. J Neurosci 24:8097-8105.

Paxinos G, Watson C (1998) In: The rat brain in stereotaxic coordinates, Ed 4. New York: Academic.

Perier C, Tremblay L, Feger J, Hirsch EC (2002) Behavioral consequences of bicuculline injection in the subthalamic nucleus and the zona incerta in rat. J Neurosci 22:8711-8719.

Puig MV, Celada P, Diaz-Mataix L, Artigas F (2003) In vivo modulation of the activity of pyramidal neurons in the rat medial prefrontal cortex by 5-HT2A receptors: relationship to thalamocortical afferents. Cereb Cortex 13:870-882.

Rosin DL, Weston MC, Sevigny CP, Stornetta RL, Guyenet PG (2003) Hypothalamic orexin (hypocretin) neurons express vesicular glutamate transporters VGLUT1 or VGLUT2. J Comp Neurol 465:593-603.

Saad WA, Guarda IFMS, Camargo LAD, Garcia G, Gutierrez LI, Saad WA, Simoes S, Guarda RS (2004) Lateral hypothalamus lesions influences water and salt intake, and sodium and urine excretion, and arterial blood pressure induced by L-NAME and FK 409 injections into median preoptic nucleus in conscious rats. Life Sci 75:685-697.

Sakurai T (2005) Roles of orexin/hypocretin in regulation of sleep/wakefulness and energy homeostasis. Sleep Med Rev 9:231-241.

Sakurai T, Nagata R, Yamanaka A, Kawamura H, Tsujino N, Muraki Y, Kageyama H, Kunita S, Takahashi S, Goto K, Koyama Y, Shioda S, Yanagisawa M (2005) Input of orexin/hypocretin neurons revealed by a genetically encoded tracer in mice. Neuron 46:297-308.

Sallanon M, Denoyer M, Kitahama K, Aubert C, Gay N, Jouvet M (1989) Long-lasting insomnia induced by preoptic neuron lesions and its transient reversal by muscimol injection into the posterior hypothalamus in the cat. Neuroscience 32:669-683.

Saper CB, Cano G, Scammell TE (2005) Homeostatic, circadian, and emotional regulation of sleep. J Comp Neurol 493:92-98.

Satoh S, Matsumura H, Fujioka A, Nakajima T, Kanbayashi T, Nishino S, Shigeyoshi Y, Yoneda H (2004) FOS expression in orexin neurons following muscimol perfusion of preoptic area. NeuroReport 15:1127-1131.

Sherin JE, Shiromani PJ, McCarley RW, Saper CB (1996) Activation of ventrolateral preoptic neurons during sleep. Science 271:216-219.

Stocker SD, Toney GA (2005) Median preoptic neurones projecting to the hypothalamic paraventricular nucleus respond to osmotic, circulating Ang II and baroreceptor input in the rat. J Physiol (Lond) 568:599-615.

Suntsova N, Szymusiak R, Alam MN, Guzman-Marin R, McGinty D (2002) Sleep-waking discharge patterns of median preoptic nucleus neurons in rats. J Physiol (Lond) 543:665-677.
Swanson LW (1998) Brain maps: structure of the rat brain, Ed 2. Amsterdam: Elsevier.

Szymusiak R, Alam N, Steininger TL, McGinty D (1998) Sleep-waking discharge patterns of ventrolateral preoptic/anterior hypothalamic neurons in rats. Brain Res 803:178-188.

Tehovnik EJ, Tolias AS, Sultan F, Slocum WM, Logothetis NK (2006) Direct and indirect activation of cortical neurons by electrical microstimulation. J Neurophysiol 96:512-521.

Thakkar MM, Mello E, Winston S, McCarley RW (2003) GABAergic control of orexinergic neurons in the regulation of behavioral states. Sleep 26:A9.

Timo-Iaria C, Negrao N, Schmidek WR, Hoshino K, Lobato de Menezes CE, Leme dR (1970) Phases and states of sleep in the rat. Physiol Behav 5:1057-1062.

Torterolo P, Yamuy J, Sampogna S, Morales FR, Chase MH (2001) C-fos expression in hypocretinergic neurons during wakefulness and carbachol-induced active sleep. Sleep 24:A155-A156.

Uschakov A, Gong H, McGinty D, Szymusiak R (2006) Sleep-active neurons in the preoptic area project to the hypothalamic paraventricular nucleus and perifornical lateral hypothalamus. Eur J Neurosci 23:3284-3296.

van den Pol AN, Acuna-Goycolea C, Clark KR, Ghosh PK (2004) Physiological properties of hypothalamic $\mathrm{MCH}$ neurons identified with selective expression of reporter gene after recombinant virus infection. Neuron 42:635-652.

Verret L, Goutagny R, Fort P, Cagnon L, Salvert D, Leger L, Boissard R, Salin P, Peyron C, Luppi PH (2003) A role of melanin-concentrating hormone producing neurons in the central regulation of paradoxical sleep. BMC Neurosci 4:19.

West AR, Moore H, Grace AA (2002) Direct examination of local regulation of membrane activity in striatal and prefrontal cortical neurons in vivo using simultaneous intracellular recording and microdialysis. J Pharmacol Exp Ther 301:867-877.

Wise RA (1972) Spread of current from the monopolar stimulation of the lateral hypothalamus. Am J Physiol 223:545-548.

Yoshida K, McCormack S, Espana RA, Crocker A, Scammell TE (2006) Afferents to the orexin neurons of the rat brain. J Comp Neurol 494:845-861.

Zhang XG, Fogel R (2002) Glutamate mediates an excitatory influence of the paraventricular hypothalamic nucleus on the dorsal motor nucleus of the vagus. J Neurophysiol 88:49-63. 